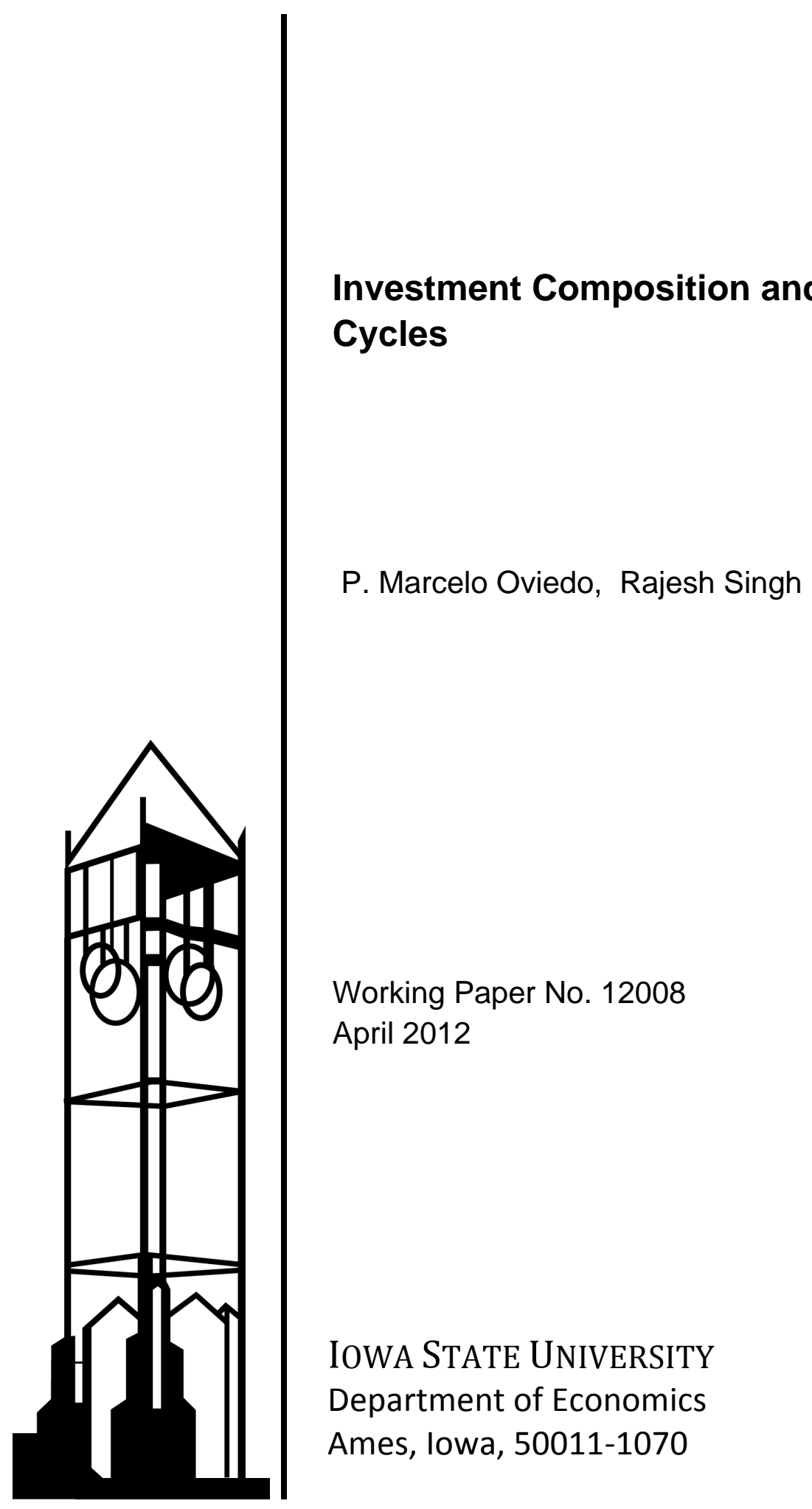

lowa State University does not discriminate on the basis of race, color, age, religion, national origin, sexual orientation, gender identity, genetic information, sex, marital status, disability, or status as a U.S. veteran. Inquiries can be directed to the Director of Equal Opportunity and Compliance, 3280 Beardshear Hall, (515) 294-7612. 


\title{
Investment Composition and International Business Cycles*
}

\author{
P. Marcelo Oviedo ${ }^{\dagger} \quad$ Rajesh Singh ${ }^{\ddagger}$ \\ Iowa State University Iowa State University
}

April 20, 2012

\begin{abstract}
This paper studies a two country model with economies disaggregated into traded and nontraded sectors and in which investment goods as in practice are produced by combining inputs from all sectors. The model also accounts for nontraded distribution services employed in retailing traded goods to consumers. The results show that the model with multiple input investments outperforms the standard model in which sectoral output also serves as its capital. In particular, it substantially improves (a) the movements of trade balance and relative prices, (b) within country comovements of sectoral and aggregate quantities, and (c) cross-country comovements of output vis-à-vis consumption.

KEYwords: International business cycles; Quantity anomaly; Distribution costs; Crosscountry correlations.

JEL Classification: F32, F34, F41
\end{abstract}

${ }^{*}$ We thank Joydeep Bhattacharya, Harvey Lapan, B. Ravikumar, and Shiva Sikdar, as well as seminar participants at Iowa State University, the 2006 North American Econometric Society meetings, and the 2007 Midwest Macroeconomics Meetings, for their comments. We also thank two anonymous referees and the editor whose suggestions have helped us improve the paper substantially. The usual disclaimer applies.

${ }^{\dagger}$ Oviedo: Department of Economics, 260 Heady Hall, Iowa State University, Ames IA 50011-1070; Phone 515-2946740; Fax: 515- 294-0221.

${ }^{\ddagger}$ Singh (Corresponding author): Associate Professor, Department of Economics, 281 Heady Hall, Iowa State University, Ames IA 50011-1070; Phone 515-294-5213; Fax: 515- 294-0221; Email: rsingh@iastate.edu 


\section{Introduction}

International business cycle models typically make simplifying assumptions on the composition of capital goods. In the two country single good model introduced by Backus, Kehoe, and Kydland (1992), consumption and capital by construction are identical goods. Even in its two goods extensions, for example in Backus, Kehoe, and Kydland (1994) and Heathcote and Perri (2003), a country specific consumption good also serves as capital. In models that include a nontraded sector, such as Stockman and Tesar (1995) and Mendoza (1995), a sector's output serves as its own capital. Some others, for example Burstein, Neves, and Rebelo (2003) and more recently Corsetti, Dedola, and Leduc (2008), assume that capital is produced only by the traded sector but is perfectly mobile across traded and nontraded sectors.

In practice, capital goods compose of both traded and nontraded goods. Based on a multicountry panel data on aggregate investments, Bems (2008) estimates that about $54 \%-62 \%$ of the expenditure is on nontraded goods. These shares however vary across sectors on further disaggregation. For example, over 1947-2004, the average US investment expenditure in the traded sector is about $69 \%$ on Equipment and Software (i.e., traded goods) while the remaining $31 \%$ is on Structures (i.e., nontraded goods); the corresponding shares for the nontraded sector are $39 \%$ and $61 \%$, respectively. Further disaggregation informs that the import content of the investment expenditure on traded goods is $37 \%$ and $36 \%$ respectively in the traded and the nontraded sector. Altogether, thus, US investment expenditure shares in the traded sector on its exportables, imports, and nontraded goods are $43 \%, 26 \%$, and $31 \%$, respectively, whereas in the nontraded sector these shares are $25 \%, 14 \%$, and $61 \%$, respectively. ${ }^{1}$

This paper adopts the above compositional shares into an otherwise standard two-country complete-markets international business cycle model as in Stockman and Tesar (1995) in which each country produces a distinct traded (exportable) good and a nontraded good and consumption preferences are defined over exportable, importable, and nontraded goods.

\footnotetext{
${ }^{1}$ After accounting for the relative sizes of the two sectors, input share estimates are broadly consistent with those reported by Bems (2008).
} 
The motivation for detailing investment composition is simple. Since investment is the most volatile aggregate in the national accounts, modeling its composition correctly within the business cycle framework will significantly impact model-generated moments. First, a sector's investment demand from other sectors is likely to align their output, employment, and investment movements and thus help explain their observed positive correlations in the data. ${ }^{2}$ Second, as output is either invested or consumed, any movements in the former will mirror in the latter as well, and thus inhibit cross-country consumption comovements encountered in standard models.

The results substantiate these conjectures. The model with investments composed of multisectoral inputs outperforms the model with sectoral output serving as its own capital on many dimensions. First, it brings the volatility of trade balance, terms of trade, relative price of nontraded goods, and real exchange rates closer to the data. Second, internal correlations of output with other aggregates, particularly the trade balance, are much improved. Within country correlations of sectoral aggregates come closer to the data. Finally, cross-country consumption correlation falls below that of output; that is, the quantity anomaly does not exist in the model with multi-input composition of sectoral investments. ${ }^{3}$

How do investments comprising multisectoral inputs improve model performance? Consider a positive supply shock in either exportable or nontraded sector in one of the countries. Compared to the model in which this sector would use its own output for investment, it instead demands more of all the three inputs: nontraded, exportables, and imports. A higher demand for the other home good as well as imports has three direct consequences. First, it raises their relative prices more. As a result, terms of trade, relative price of nontraded goods, and real exchange rates are

\footnotetext{
${ }^{2}$ In a closed economy model, Hornstein and Praschnik (1997) show that the use of intermediate inputs in production helps explain within country positive crosssectoral output and employment comovements. Their two sectors are durables and nondurables. Durables produce capital for use in both sectors, while nondurables produce consumption and intermediate inputs for durables' production.

${ }^{3}$ That cross-country consumption correlation substantially exceeds output correlation in an international business cycle model, at complete variance with the data, was first highlighted and dubbed as the "quantity anomaly" by Backus, Kehoe, and Kydland (1992). Their model economy comprised of two countries, a single consumption good, and complete financial markets.
} 
relatively more volatile. Second, a higher import expenditure on investment leads to a higher trade variability and countercyclicality of the trade balance. Third, within-country sectoral outputs and therefore their employments and investments are more aligned.

As for cross-country consumption comovements, consider first a positive productivity shock in the exportable sector in, say, country 1 . In the model with a sector's output serving as its own capital, a part of the increased exportable output will be used for investment and the remaining shared between the two countries' consumption. A higher traded consumption raises demand for non traded goods as well. Both countries' nontraded prices and output respond to increased consumption demand symmetrically. When investments instead comprise multisectoral goods, country 1's investment demand for its nontraded goods now crowds out its nontraded consumption demand. Consumption's compositional responses are not symmetric across countries any more, thus inhibiting their aggregate comovements. Now consider a positive shock to the nontraded sector of country 1 . With nontraded sector's investment not solely absorbing its own output, more of it is left for consumption that by its very nature can not be shared across countries. Moreover, country 1's investment demand for imports is supported by cutting country 2's traded consumption. Cross-country consumption comovement is further inhibited. As a result, the quantity anomaly disappears once multisectoral composition of investments is introduced.

The last result is of particular significance because the anomaly has puzzled international macroeconomists for about two decades. Researchers have resorted to various strategies to resolve this puzzle, restricting asset trades and introducing nontraded goods in particular, since tradablity of goods and assets is at the heart of consumption sharing across countries. ${ }^{4}$ These strategies have met with only partial success. Table 1 summarizes the relative success of past studies in this respect.

\section{Table1}

Merely restricting asset trade does not help. Baxter and Crucini (1995) show that with trend-

\footnotetext{
${ }^{4}$ The anomaly has also been addressed by incorporating (a) multiple sectors with trade in intermediate inputs (see, for instance, Ambler et al. (2002), Kouparitsas (1997), and Huang and Liu (2004)), and (b) multiple countries (see, for instance, Yakhin (2005)).
} 
stationary shocks a sole riskless bond is almost as good as complete markets in letting countries pool consumption intertemporally; one needs unit root shocks in addition to hinder consumption sharing in the bond economy. Kollman (1996) in a bond economy with shocks more persistent than those estimated by Backus, Kehoe, and Kydland (1992) thus obtains a much lower cross-country consumption correlation than previous studies. Kehoe and Perri (2003) endogenize market incompleteness by introducing 'enforcement constraints' and with shocks as persistent as Kollman (1996) obtain a substantial improvement in the relative ordering of quantity correlations. Heathcote and Perri (2002) completely eliminate assets trade. Still, the consumption correlation largely exceeds the output correlation.

Stockman and Tesar (1995), while retaining market completeness, introduce nontraded goods into the model hoping to restore internal consumption-output comovement and to inhibit crosscountry consumption comovement. But the model solely driven by technology shocks obtains a high cross-country correlation (0.94) between consumption of traded goods and as a result the crosscountry aggregate consumption correlation exceeds that of the aggregate outputs. Then they bring in taste shocks which lowers cross-country correlation of consumption, yet the quantity anomaly survives.

What does help is a consumption bias towards exportable good relative to the imported good and/or a low elasticity of substitution between the two (i.e., low trade elasticity). ${ }^{5}$ Thus, to match data correlations, Heathcote and Perri (2003) assume home bias in a two traded-goods model with limited asset trade and unit root shocks. As for a low trade elasticity, Pakko (1997) argues that a higher compositional risk aversion than the aggregate induces consumers to let aggregate consumption fluctuate in order to stabilize its composition. This inhibits cross-country consumption sharing. With a low trade elasticity as well as home bias, Corsetti, Dedola, and Leduc (2008) study risk sharing in a two-country world with both traded and nontraded goods and asset trade restricted to a single bond. The quantity anomaly does not appear in their results. ${ }^{6}$

\footnotetext{
${ }^{5}$ There is no clear consensus however on the magnitude of these trade elasticities. While micro studies pose it to be as high as 4 , in macro literature it is found anywhere between $0.5-2$.

${ }^{6}$ The main intent of their paper is to resolve Backus-Smith puzzle by showing that a low elasticity of substitution
} 
This paper thus contributes to the above literature by highlighting a novel transmission mechanism. It shows that merely accounting for a realistic input output structure in the production of capital goods eliminates quantity anomaly from the workhorse two-sector international business cycle model without restricting shocks or trade in assets.

Another point of departure from Stockman and Tesar (1995) in this paper is in the role of distribution services. ${ }^{7}$ While Stockman and Tesar (1995), due to data constraints, classify distribution and transportation services as traded goods, the present study counts them as part of nontraded output. In the data used in this paper, the ratio of traded to nontraded output is about 0.44 while the corresponding ratio of consumption expenditures is about 0.62 . These ratios can be reconciled only if distribution costs entailed in retailing traded goods are explicitly recognized. The benchmark model accordingly incorporates a distribution sector that, as in the data, utilizes inputs of exportables, importables, and nontraded goods to produce its services. ${ }^{8}$ Following past studies, it is assumed that a fixed per unit distribution cost is incurred in retailing traded goods.

Burstein, Neves, and Rebelo (2003) conjecture that introducing distribution costs may help preclude quantity anomaly. The rationale is that distribution services can be equivalently thought of as consumption preferences with stronger complementarity between traded and nontraded goods, i.e., a higher compositional risk aversion; then the desire to smooth aggregate consumption becomes less pressing. Thus an obvious question arises: To what extent are the resolution of quantity anomaly and other improvements in this paper's model vis-à-vis Stockman and Tesar (1995) model predicated by an explicit role for distribution services?

The results change marginally when the model somewhat counterfactually abstracts from distribution services. A reconciliation of sectoral consumption expenditures with respective outputs and home bias in consumption in a bond economy leads to wealth effects that require terms of trade appreciation in case of a positive output shock (and vice versa).

${ }^{7}$ In recent years, researchers have explained several international relative-price puzzles by explicitly modeling distribution services, i.e., the transportation, wholesaling, and retailing services, as nontraded component of traded consumption. See, for example, Burstein, Neves, and Rebelo (2003), Corsetti and Dedola (2005), and Corsetti, Dedola, and Leduc (2008).

${ }^{8}$ See Campa and Goldberg (2006) who provide a detailed break up of the inputs utilized to produce distribution services in a large set of countries. 
is only possible if distribution and transportation services are classified as traded output, as in Stockman and Tesar (1995). The relative size of traded to nontraded output then inflates to 0.72. A recalibration of the model leads to two key changes in preferences. Since distribution services are bundled with exportables, the share of imports within traded consumption falls leading to an increase in home bias. Second, the elasticity of substitution between traded and nontraded consumption falls as conjectured by Burstein, Neves, and Rebelo (2003). A larger traded sector calls for a higher cross-country consumption comovement, but a higher home bias and a lower elasticity counteract it. The result is only a marginal rise in cross-country consumption correlation from 0.27 to 0.28 , while that of output rises from 0.45 to 0.46 . The other changes in the results are equally minor. The exercise thus unambiguously establishes that a careful accounting of the input composition of investments is the key to improvements that benchmark model achieves over its competing versions.

The remainder of the paper is organized as follows. The next section summarizes the main characteristics of the data that the model attempts to explain. Section 3 provides a simple two-goods extension of Backus, Kehoe, and Kydland (1992) model. It shows how cross-country consumption comovements are lowered when investments are relatively more import intensive. The full model is then presented in Section 4. Section 5 first estimates input shares for producing capital goods

and distribution services in the US. Armed with these share, the rest of this section calibrates the remaining parameters of the model. The results are presented in Section 6. This section compares the benchmark model with (a) its version in which sectoral outputs serve as their own capital, (b) its version that abstracts from distribution services, and (c) the Stockman and Tesar (1995) model. Section 7 offers some concluding remarks.

\section{Business cycle statistics}

This section presents empirical regularities of some key variables that the paper's model attempts to reproduce. Since the model economy consists of traded and nontraded sectors, the empirical 
moments presented here include sectorwise cross-country and domestic cross-sectoral moments. The set of moments presented here are later in Section 6 compared with the data generated by alternative versions of the theoretical model.

The data relating to the G7 and an European aggregate EU15 span 1970-2003 at annual frequency. ${ }^{9}$ Industrywise data on output, prices, and employment have been obtained from Groningen Growth Development Center (GGDC); sectorwise consumption data is from OECD Statistics (National Accounts) and investment is from OECD Structural Analysis (STAN) database. The data on trade balance, real exchange rate, and terms of trade are obtained from International Financial Statistics. Further details are provided in an appendix. All moments reported below are computed after detrending the data with HP filter.

\subsection{Volatilities and internal correlations}

Table 2 presents standard deviations of output, consumption, investment, and employment. Barring UK and Canada, traded output is more volatile than its nontraded counterpart. In particular, for EU15 and the US, the differences are much larger. Table 2 confirms that consumption is generally less volatile than the output, not only in the aggregate but also sectorwise. Also, as with output, traded consumption is more volatile than nontraded consumption.

Table 2

As is well known, investment exhibits a much higher volatility than the output (2.4 to 3.5 times in Table 2). Within investment, the traded sector component is substantially more volatile than its nontraded counterpart. Next, employment is about as volatile as output except in Japan where it is less than half of its output. As with other aggregates, traded sector employment is more volatile than the nontraded sector.

The volatilities of trade variables are reported in Table 3 . Trade balance is much less volatile

\footnotetext{
${ }^{9}$ G7 includes Canada, France, Germany, Italy, Japan, UK and USA. The countries under EU15 are Austria, Belgium, Denmark, Finland, France, Germany, Greece, Ireland, Italy, Luxembourg, Netherlands, Portugal, Spain, Sweden and the UK.
} 
than the output; for the US it is about a quarter, while for the rest it is close to a half of the output. Terms of trade, except for the UK, are more volatile than output; for the US it is about the same, while for the EU15 it is almost two and a half times. Finally, real exchange rates, as is well known, are highly (about 3 - 8 times) volatile relative to output.

Table 3

Table 3 also reports domestic correlations of aggregate consumption, investment, employment, and trade balance with output. As is well known, the first three are highly procylical, ${ }^{10}$ and the last (trade balance) is significantly countercyclical. As for internal comovements, sectoral outputs exhibit high positive comovement; in UK, Japan, Germany and Canada the correlation is 0.99. Sectoral consumptions, except in Japan, exhibit strong positive comovement. The same holds for sectoral employments. The correlation of sectoral investments, however, is lower than the other three; for Germany it is negative. ${ }^{11}$

Many properties of the data discussed above have been reported in the previous studies. What has not particularly been highlighted earlier is that (a) volatilities of traded sector aggregates are relatively higher and (b) sectoral outputs, consumption, and employment comove strongly together; the comovement of sectoral investments is weaker. These data moments will be set as performance targets in Section 6, while comparing results from theoretical alternatives.

\subsection{Cross-country comovements}

Table 4 reports correlations of output, consumption, investment, and employment of US vis-àvis other G7 countries and EU15. As evident, aggregate consumption is less correlated than the output. In particular, the aggregate output correlation is 0.61 for the US-EU15; that of consumption it is $0.47 .^{12}$ The comovement of US sectorwise outputs and consumptions with that of other

\footnotetext{
${ }^{10}$ As one can conjecture from Japan's low employment volatility, its employment correlation with output at 0.48 is much lower than in other countries.

${ }^{11}$ It is worth noting that for Germany the data spans only 1991 - 2003.

${ }^{12}$ The correlations for the entire set of country pairs is reported in Table 15. The averages of crosscountry output and consumption correlations for the entire set of countries is 0.56 and 0.48 , respectively.
} 
countries (barring Japan and Italy) are positive and somewhat similar in magnitude to aggregate comovements; no clear pattern emerges on their relative magnitudes. ${ }^{13}$

Table 4

Cross-country investment correlations are generally low. As reported in Table 4, it is 0.27 for US-EU15, while the average between US and others is $0.32 .{ }^{14}$ Sectorwise correlations exhibit wide variations and frequently switch signs. For traded and nontraded sectoral investments, the average correlation between US and others is 0.13 and 0.32 , respectively. ${ }^{15}$

Finally, barring US-Italy and US-Germany, the correlation pattern of aggregate as well sectoral employments are somewhat similar to that of output. In particular, the ES-EU15 correlations are $0.61,0.37$, and 0.42 , respectively, for aggregate, traded and nontraded output; their employment counterparts are $0.43,0.33$, and 0.49 .

The above correlations, in particular of US-EU15 whenever available, will be set as performance targets for the quantitative evaluation of alternative theoretical models in Section 6.

\section{Cross-country correlations of output and consumption in a world economy with two goods}

In the model economy calibrated in Section 5, traded consumption expenditure is about $37.5 \%$ of total consumption. After accounting for the expenditure on distribution services, the import content of total consumption turns out to be only 10\%. As for investments, the expenditure on imports in the traded sector is $26 \%$, while in a relatively (2.25 times) larger nontraded sector it is

\footnotetext{
${ }^{13}$ Japan turns out to be an outlier with its traded consumption substantially negatively correlated with the rest of the world except Germany.

${ }^{14}$ Given its large variability, a better indicator for crosscountry investment correlation may be the average for the entire set of country pairs, which turns out to be 0.43 .

${ }^{15}$ Since the only five available US-others sectoral investment correlations exhibit large variability, a more reliable proxy is the average for the entire set of country pairs: it is 0.26 and 0.38 for the traded and nontraded sectors, respectively.
} 
14\%. Altogether, total investment expenditure on imports is about $18 \%{ }^{16}$ Investments command a larger output sharing across countries, relative to consumption, which partly explains why the quantity anomaly disappears in this paper's model. To illustrate this point, a two-goods extension of Backus, Kehoe, and Kydland (1992) model is presented below. The full model that explicitly includes a nontraded sector is developed in the next section.

There are two symmetric countries, indexed by 1 and 2. Each of them produces a distinct exportable good. The good exported (imported) by country 1 is denoted as the $x$-good ( $m$-good). The symmetry across countries allows to economize on notation by only describing country 1's problem. When necessary, country 2's variables are referred to by using asterisks.

In Backus, Kehoe, and Kydland (1992), a single homogenous good is perfectly mobile across countries for both consumption and investment. In its two-goods extensions by Backus, Kehoe, and Kydland (1994) and Heathcote and Perri (2003), for example, each country produces a unique intermediate good which is then combined to produce a final good for within-country consumption and investment. Specifically, the goods market equations are

$$
\begin{aligned}
x_{t}+x_{t}^{*} & =y_{t} \equiv z_{t} f\left(k_{t}\right), \\
c_{t}+\underbrace{k_{t+1}-(1-\delta) k_{t}}_{i_{t}} & =x_{t}^{\theta} m_{t}^{1-\theta},
\end{aligned}
$$

where $z, k$, and $c$ denote productivity, capital stock, and consumption, respectively; $\theta \in(0,1)$ is the expenditure share of exportables in the final good production. For simplicity, it is assumed here that labor is inelastically supplied. Equation (1a) represents the division of country 1's output of intermediate goods between the two countries. Equation (1b) shows how country 1's share of its own output is combined with imports from country 2 to produce the final good.

A similar set of equations exist for country 2 , where $x^{*}$ and $m^{*}$ combine to produce a final good for its consumption and investment. Let $u($.$) denote a standard utility function. Under complete$

\footnotetext{
${ }^{16}$ Engel and Wang (2011) report the import component of investment and consumption expenditures to be about $30 \%$ and $10 \%$, respectively.
} 
markets, the allocation problem boils down to maximizing

$$
\sum_{t=0}^{\infty} \beta^{t}\left(u\left(c_{t}\right)+u\left(c_{t}^{*}\right)\right)
$$

subject to (1a) and (1b) and its country 2 equivalents.

Optimality commands that for both intermediate goods $x$ and $m$, the MRT into the final (consumption) good of country 1 and 2 equal their MRS for consumption. That is,

$$
\frac{u^{\prime}\left(c_{t}\right)}{u^{\prime}\left(c_{t}^{*}\right)}=\frac{\frac{(1-\theta) m_{t}^{* \theta} x_{t}^{* 1-\theta}}{x_{t}^{*}}}{\frac{\theta x_{t}^{\theta} m_{t}^{1-\theta}}{x_{t}}}=\frac{\frac{\theta m_{t}^{* \theta} x_{t}^{* 1-\theta}}{m_{t}^{*}}}{\frac{(1-\theta) x_{t}^{\theta} m_{t}^{1-\theta}}{m_{t}}}
$$

which gets

$$
\frac{\theta}{1-\theta} \frac{m_{t}}{x_{t}}=\frac{1-\theta}{\theta} \frac{m_{t}^{*}}{x_{t}^{*}}
$$

If the final goods technology has no input bias, i.e., $\theta=\frac{1}{2}$, then

$$
c_{t}=c_{t}^{*}
$$

consumption is perfectly shared across countries. The intuition is simple. With no home bias in inputs, an efficient (constant) scale of final goods production is obtained by identically apportioning both intermediated goods. This allows the planner to give equal consumption to both, and then choose the relative investments as governed by the productivity process. However, in a more plausible scenario of a home bias the country with a positive shock will obtain a higher consumption and its cross-country comovements will be inhibited. For $\theta=1$, the economies are closed and consumption and output movements will be closely aligned. Finally, output correlations will be governed by the productivity process and the transmission of shocks across countries through relative investments.

To capture a relatively higher import intensity for investments in the data, consider now the following version of the model in which a country's output is nontraded for consumption, but traded 
for producing capital. ${ }^{17}$ Specifically,

$$
\begin{aligned}
c_{t}+x_{t}+x_{t}^{*} & =y_{t} \equiv z_{t} f\left(k_{t}\right), \\
\underbrace{k_{t+1}-(1-\delta) k_{t}}_{i_{t}} & =x_{t}^{\theta} m_{t}^{1-\theta} .
\end{aligned}
$$

An efficient allocation now requires that the relative valuation of the two countries' consumption goods evaluated at their respective marginal utilities be equalized to their relative valuation in terms of their marginal product (as inputs) in the two investment goods:

$$
\frac{u^{\prime}\left(c_{t}\right)}{u^{\prime}\left(c_{t}^{*}\right)}=\frac{\theta}{1-\theta} \frac{m_{t}}{x_{t}}=\frac{1-\theta}{\theta} \frac{m_{t}^{*}}{x_{t}^{*}}
$$

Let $u \equiv \ln$ and $\theta=\frac{1}{2}$. Then

$$
\frac{c_{t}}{c_{t}^{*}}=\frac{x_{t}}{m_{t}}=\frac{x_{t}^{*}}{m_{t}^{*}}=\frac{y_{t}}{y_{t}^{*}}
$$

where the last equality follows from (2a). With unit elasticities of substitution and no home input bias in investment production, optimality thus commands that each country's output be apportioned into domestic consumption and investment inputs in country 1 and 2 identically, i.e.,

$$
\frac{c_{t}}{y_{t}}=\frac{c_{t}^{*}}{y_{t}^{*}} ; \frac{x_{t}}{y_{t}}=\frac{m_{t}}{y_{t}^{*}} ; \frac{x_{t}^{*}}{y_{t}}=\frac{m_{t}^{*}}{y_{t}^{*}} .
$$

In contrast with the model with a homogenous consumption and investment good that equalizes consumption, it is now the consumption to output ratio that is equalized across countries. This restores within country output-consumption comovement: a country with a higher output now enjoys a higher consumption. Indeed, it is now even plausible that cross-country consumption correlation is negative.

To see this, assume a bivariate $\operatorname{AR}(1)$ process for $\left\{z, z^{*}\right\}$, as estimated by Backus, Kehoe, and Kydland (1992); and, for simplicity, assume that there are no spillovers, i.e., the off-diagonal elements in the autocorrelation matrix are zero. ${ }^{18}$ Consider now a high realization of $z$. A rise

\footnotetext{
${ }^{17} \mathrm{~A}$ more realistic model will have both consumption and investment as composites of exports and imports, and assume a lower share parameter for imports within the consumption aggregator. For simplicity, here it is assumed to be 0 .

${ }^{18}$ The $2 \times 2$ autocorrelation matrix estimated by Backus, Kehoe, and Kydland (1992) has 0.906 at the diagonals and 0.088 at the off-diaongals. Positive spillovers will further strengthen the results that follow.
} 
in output will raise consumption, but expecting a high future productivity, country 1 may assign a relatively higher portion of its extra output towards its investment. If the percentage rise in consumption is less than its percentage rise in output, the ratio $\frac{c_{t}}{y_{t}}$ falls. Since country 2's output has remained the same, this requires country 2's consumption to fall. This, in turn, is justified by a higher supply of its output for country 1's increased investment. As a result, cross-country consumptions comove negatively.

The above intuition is confirmed by the following simulation results. Let $f(k)=k^{0.4}, u \equiv$ $\ln , \beta=0.99$, and $\delta=0.025$. Then, Figure 1 below presents the quantity correlations for the two versions discussed above.

\section{Figure 1}

Evidently, for all plausible values of $\theta \in[0.5,1]$, cross-country output correlations always fall below the consumption correlations in the first version. The consumption correlation is unity for $\theta=\frac{1}{2}$, and converges closer to output correlation as $\theta \rightarrow 1$. In the second version the situation is reversed. Indeed, the cross-country consumption correlation remains negative for $\theta$ as high as 0.8. While the results assume logarithmic utilities, the relative shapes survive for intertemporal elasticities of substitution between 0.5 and 2 , as has been verified numerically.

The basic intuition behind the above two contrasting results is that in the first version consumption and investment are identical goods and both can be adjusted through exchange of intermediate goods. A windfall in one country can then be shared in another. However, in the second version, while capital goods can be adjusted by exchange of traded goods, the consumption is nontraded. Here the planner does not want to increase foreign consumption in response to a positive domestic shock, and the cross-country consumption correlation is reduced.

The next section develops the paper's benchmark model that explicitly includes a nontraded sector. 


\section{The model}

This section extends the two-country, three-good complete market model of Stockman and Tesar (1995) along two dimensions. First, capital goods are produced by combining all goods: exportable, importable, and nontraded goods as inputs. Second, as in Burstein, Neves, and Rebelo (2003), traded goods can be delivered to consumers only after utilizing distribution services. ${ }^{19}$ These services, as with capital goods, are produced by combining both traded and nontraded goods as inputs.

The model retains the environment and notations described in Section 3. However, in addition to $x$-good and $m$-good produced by countries 1 and 2, respectively, both countries now also produce a nontraded good denoted as the $n$-good $\left(n^{*}\right)$ for country $1(2)$.

Intermediate and final goods production Exportable and nontraded goods are produced with sector-specific Cobb-Douglas technologies that combine sector-specific capital $(k)$ and labor (h) to produce output:

$$
y_{i t}=\lambda_{i t}\left(k_{i t}\right)^{\theta_{i}}\left(h_{i t}\right)^{1-\theta_{i}} ; i=x, n
$$

where $\lambda$ denotes productivity shocks, and $\theta \in(0,1)$ is the standard capital-share parameter; the subscript $i$ specifies output sectors and $t$ indexes time. The sectoral technology shocks are assumed to evolve according to the following $\operatorname{VAR}(1)$ process:

$$
\lambda_{t+1}=\Lambda \lambda_{t}+\varepsilon_{t}
$$

where $\boldsymbol{\lambda}_{t} \equiv\left[\lambda_{x t}, \lambda_{n t}, \lambda_{m t}^{*}, \lambda_{n t}^{*}\right] ; \boldsymbol{\Lambda}$ is a $4 \times 4$ symmetric matrix of autoregressive coefficients; and $\varepsilon_{t} \equiv$ $\left[\varepsilon_{x t}, \varepsilon_{n t}, \varepsilon_{m t}^{*}, \varepsilon_{n t}^{*}\right]$ is a vector of i.i.d. innovations with a known covariance matrix $\boldsymbol{\Sigma}$.

Exportable and nontraded goods along with imports serve as intermediate goods for producing

\footnotetext{
${ }^{19}$ Since distribution services utilize mostly (about 85\%) nontraded goods, instead of decomposing nontraded consumption expenditure into its distribution and nondistribution components, they are assumed to be homogeneous. See, for example, Burstein et al. (2003), and Coresetti et al. (2008).
} 
capital for the exportable and nontraded sectors, as well as distribution services ${ }^{20}$ :

$$
s_{i t}=\mu_{i}\left(\phi_{i} x_{i t}^{-\epsilon_{i}}+\left(1-\phi_{i}\right) m_{i t}^{-\epsilon_{i}}\right)^{-\frac{\alpha_{i}}{\epsilon_{i}}}\left(n_{i t}\right)^{1-\alpha_{i}}, \quad i=d, x, n .
$$

Here $s$ represents output; $\mu$ is a time-invariant scale parameter; $x, m$, and $n$ denote inputs of exportable, importable, and nontraded goods respectively; $\phi, \alpha \geq 0$ are input-share parameters; $(1+\epsilon)^{-1}$ is the elasticity of substitution between $x$ and $m \cdot{ }^{21}$ While distribution services are utilized within the same period (see (9) below), the investments undertaken in the two sectors mature in one period:

$$
k_{i t+1}=\left(1-\delta_{i}\right) k_{i t}+s_{i t}, \quad i=x, n,
$$

where $\delta_{i}$ denotes the depreciation rate of capital in sector $i$.

The consumption good is composed of the three intermediate goods:

$$
c_{t}=\left[\omega\left(\left(\nu c_{x t}^{-\sigma}+(1-\nu) c_{m t}^{-\sigma}\right)^{-\frac{1}{\sigma}}\right)^{-\rho}+(1-\omega) c_{n t}^{-\rho}\right]^{-\frac{1}{\rho}},
$$

where $c_{x}, c_{m}$, and $c_{n}$ denote the consumption of exportables, importables, and nontraded goods; $\nu$ and $\omega$ are expenditure share parameters; $(1+\sigma)^{-1}$ is the elasticity of substitution between $c_{x}$ and $c_{m}$; and $(1+\rho)^{-1}$ is the elasticity of substitution between the traded consumption composite and $c_{n}$. When $\sigma=1$, the functional form of the consumption composite (7) nests Stockman and Tesar (1995).

Resource constraints While the nontraded output is entirely absorbed internally, an amount $e_{x}$ of the exportable good is shipped abroad. Thus, the resource constraints related to the two intermediate goods are:

$$
\begin{aligned}
c_{x t}+\sum_{i=d, x, n} x_{i t}+e_{x t} & \leq y_{x t} \\
c_{n t}+\sum_{i=d, x, n} n_{i t} & \leq y_{n t} .
\end{aligned}
$$

\footnotetext{
${ }^{20}$ See Campa and Goldberg (2006), who provide a detailed break up of the inputs utilized to produce distribution services in a large set of countries.

${ }^{21}$ Bems (2008) reports that shares of traded and nontraded components of investment expenditures have been fairly stable over time, thus providing a rationale for using Cobb-Douglas technology for the production of capital goods.
} 
It is assumed that $\psi$ units of distribution services are utilized for each unit of an exportable or an importable good to make them consumable. Thus, the production and absorption of distribution services satisfy:

$$
s_{d t} \geq \psi\left(c_{x t}+c_{m t}\right)
$$

Finally, as country 1's exports are country 2's imports and vice-versa, the following worldwide constraint on the use of importables (exportables) must hold:

$$
c_{m t}+\sum_{i=d, x, n} m_{i t} \leq e_{m t}^{*}
$$

where $e_{m}^{*}$ is the export (import) of good $m$ by country 2 (1).

Household preferences The representative household is endowed with a unit of labor which it allocates between labor $h_{t}\left(=h_{x}+h_{n}\right)$ and leisure $1-h_{t}$. The household's preference over an uncertain infinite stream of consumption $\left(c_{t}\right)$ and leisure is given by

$$
U=E_{0} \sum_{t=0}^{\infty} \beta^{t} \frac{c_{t}^{\gamma}\left(1-h_{t}\right)^{\eta}}{\gamma},
$$

where $\beta \in(0,1)$ is the discount factor; $(1-\gamma)^{-1}$ is the intertemporal elasticity of consumption substitution; and $\eta$ is the share parameter of leisure in utility.

The planner's problem Since complete contingent-claims markets are assumed to exist, the allocations of the decentralized world competitive equilibrium are identical to the allocations obtained by a social planner who maximizes the country-weighted sum, $\zeta U+(1-\zeta) U^{*}$, where $\zeta \in(0,1)$ is the weight in total welfare the planner gives to country 1 . The constraints of the planner's maximization problem are equations (3) to (10) for country 1, and a similar set of equations for country 2 .

The above benchmark model nests Stockman and Tesar's model by (a) assuming that each sector's capital goods be produced by using exclusively its own final good, which amounts to setting $\phi=\alpha_{x}=1$ and $\alpha_{n}=0$ in (5); (b) eliminating the distribution services by setting $s_{d t}=\psi=0$ in 
(9); and (c) adding an exogenous, constant growth rate of labor-augmenting productivity, which requires re-expressing the model to induce stationarity.

\section{Model calibration}

For sectoral traded and nontraded GDP value-added aggregation, 60-industry data provided by GGDC is utilized. The traded sector of GDP includes Agriculture, forestry, and fishing; Mining and quarrying; and Manufacturing. The rest are in the nontraded sector (see the data appendix for further details). Retail and wholesale services, transportation services, and services of restaurants and hotels are included in the nontraded sector, whereas Stockman and Tesar (1995) bundle them in the traded sector due to data constraints. ${ }^{22}$ From 1979-2004, these services account for about $15 \%$ of GDP, not only in the US, but also in the European aggregate EU15, and this share has remained fairly stable over time. With these services included, the size of nontraded output on an average is 2.25 times its traded counterpart, whereas in Stockman and Tesar (1995), the GDP is evenly split between the two components.

The two subsections below calibrate parameters for the model of the previous section. The first presents an estimate, via an input-output accounting exercise, of input shares of the US production of capital goods and distribution services. The second completes the calibration of the remaining parameters of the model.

\subsection{Investment goods and distribution services: input shares}

The goal here is to calibrate the shares of exportables, importables, and nontraded inputs used in the production of capital and distribution services. The estimates are shown in Tables 5 and 6 , respectively.

These estimates are based on the industry-wise investment data reported by the Bureau of Economic Analysis (BEA). From 1947-2004, these data identify two types of investment, namely

\footnotetext{
${ }^{22}$ See footnote 11 in Stockman and Tesar (1995).
} 
Equipment \& Software (E\&S) and Structures. ${ }^{23}$ For the traded sector of the US economy, the share of investment expenditure on E\&S is $69 \%$ on average, and the remaining $31 \%$ is on Structures. For the nontraded sector, the shares are $39 \%$ on E\&S, and $61 \%$ on Structures.

In E\&S, the BEA includes "machinery, equipment, furniture, vehicles, and computer software," all of which are traded goods according to the GDP value-added classification of this paper. On the other hand, the BEA defines Structures as the "products that are usually constructed at the location where they will be used and that typically have long economic lives." Following the sectoral classification of construction industry, Structures are henceforth treated as nontraded goods.

The next step is to decompose traded inputs, E\&S, into exportables and importables, as has been reported in the two central columns of Table 5. This is done by utilizing the BEA table of "Exports and Imports of Goods and Services by Type of Product" from 1967-2004, which identifies three items as investment goods: durable goods for industrial use, capital goods, and automotive vehicles, engine, and parts. However, the last category includes consumers' purchases of vehicles. The BEA's benchmark 1997 import matrix, which indicates that about $32.4 \%$ of automotive imports are allocated to private fixed investment, helps to apportion the investment component of automotive imports.

The BEA export-import data can be combined with the BEA industry-wise investment data to obtain the total annual import expenditure series (1967-2004) for private fixed investment. For example in 1997, the import expenditures on durable goods for industrial use, capital goods, and automotive vehicles, engines, and parts were equal to 69.2, 253.4, and 139.5 (current) billion dollars, respectively. By excluding consumer imports of automotive products, the total import expenditure for private fixed investment in that year turns out to be 367.8 billion dollars $(=69.2+253.4+139.5 \times 0.324)$.

The question now is how to impute these imports to the E\&S investments made by the traded and nontraded final goods sectors. This is resolved by following the methodology the BEA uses to

\footnotetext{
${ }^{23}$ The corresponding tables in the BEA database are Table 3.7E, "Historical-Cost Investment in Private Equipment and Software by Industry;" and Table 3.7S, "Historical-Cost Investment in Private Structures by Industry."
} 
compute its commodity import matrix. The BEA imputes imports of commodities to industries by using the proportions in which these industries demand domestically supplied goods. Adhering to this convention requires that the imports of capital goods be imputed to the traded and nontraded sectors with the same ratios as the ones observed for their total investment on these capital goods. For the 1997 example discussed above, 28\% of the economy-wide investment on E\&S goes to the traded sector, and the remaining $72 \%$ to the nontraded sector. Then the imputed traded and nontraded sector's import expenditure on investment goods becomes $103(=367.8 \times 0.28)$ and $264.8(=367.8 \times 0.72)$, respectively. Similar calculations obtain a time series (1967-2004) for total import expenditures on investment goods by the two sectors.

Recall that each sector's total investment on traded inputs was obtained right at the beginning of this exercise. A simple division of the import series by the total traded input series obtains an average imports to total traded input ratio of 0.37 for the traded sector, whereas for the nontraded sector the ratio equals 0.36. Applying these ratios to the expenditure shares of traded inputs, 0.69 and 0.39 in the traded and nontraded sectoral investments, respectively, obtains the expenditure shares on domestically produced traded goods (exportables) and on importables, as reported in Table 5 .

As for distribution services, Burstein, Neves, and Rebelo (2003), and Campa and Goldberg (2006), have quantified their role in the delivery of traded goods to consumers. These studies measure the "distribution margin" as the value of the wholesale and retail trade component (both considered as nontraded goods) incorporated into the value of the private final consumption of traded goods.

Following Burstein, Neves, and Rebelo (2003), it is assumed below that only the following GDP sectors utilize wholesale and retail services: Agriculture, Forestry, Fishing \& Hunting; and Mining, and Manufacturing. The remaining sectors mainly consist of services in which the distribution margin is assumed to be zero. These assumptions, along with yearly BEA input-output tables, allow one to obtain the estimates of the US distribution margins reported in Table 6 . The table also presents distribution margins for the US and the nations that represent the second country in 
the model. The average distribution margin for these countries equals $41.6 \%$, according to estimates obtained by Burstein, Neves, and Rebelo (2003).

As for the input shares of intermediate goods utilized in producing distribution services, Table 5 shows the estimates following a strategy similar to the one used for deriving the input shares for capital goods, and it is based on the BEA's 1997 benchmark input-output table and the BEA's 1997 import matrix.

\subsection{Other model parameters}

The benchmark model is calibrated to the US data, which in the case of value-added across sectors, are roughly consistent with the data of the European aggregates EU15 and EU5 (France, Germany, Italy, Netherlands, and UK), and of a group of five countries (Canada, France, Germany, Italy, and UK). The data sources are BEA, BLS, OECD, and GGDC statistics. All parameter values are summarized in Table 7.

The average ratio of value-added in the nontraded sector to that in the traded sector turns out to be 2.25 (BEA, 1947:2005, GDP value-added by sector). Labor compensation in the US equals $64 \%(62 \%)$ of the value added in the traded (nontraded) sector (GGDC, 1979-2003); thus, $\theta_{x}=0.36$ and $\theta_{n}=0.38$. As in previous studies, $\beta$ is set equal to 0.96 . It is assumed that households allocate $30 \%$ of their time to market activities, and that labor is perfectly mobile across sectors. Then, given the values of the sectoral outputs, those of $\theta_{x}$ and $\theta_{n}$, the labor constraint $h=h_{x}+h_{n}$, and the equality of wages across sectors, the steady-state values of the following can be obtained: sectoral labors, $h_{x}$ and $h_{n}$, sectoral capital stocks, $k_{x}$ and $k_{n}$, and the steady state values of final goods technology parameters, $\lambda_{x}$ and $\lambda_{n}$.

The BLS reports an average depreciation rate of $12 \%$ for E\&S and $5 \%$ for Structures. It also reports that the capital stock is equally divided between E\&S and Structures in the farm and manufacturing sectors (traded sectors), while the respective fractions in the non-farm, nonmanufacturing sectors (nontraded sectors) are 30\% and 70\%. Accordingly, the depreciation rates in the traded and nontraded sectors are set to $\delta_{x}=0.5 \times(0.12+0.05)=0.085$ and $\delta_{n}=0.30 \times$ 
$0.12+0.7 \times 0.05=0.071$, respectively. The values of $\delta_{x}, \delta_{n}, k_{x}$ and $k_{n}$ determine the output of the industries that produce capital goods, $s_{x}$ and $s_{n}$.

The benchmark parameter values shown in Table 7 are based on a unit trade elasticity for all traded composites; i.e., $\sigma=1$; and $\epsilon_{i}=1$, for $i=d, x, n .^{24}$ This induces Cobb-Douglas technologies for producing capital goods and services, whose input shares are then set to those in Table 5. The values of input shares, along with the quantity of inputs and outputs of the capital goods industries, obtains the scale parameters $\mu_{x}$ and $\mu_{n}$.

Following the evidence presented earlier, the distribution margin is set to $41.6 \%$, and consistent with the US data, the GDP share of exports of goods is 12\% (BEA 1951: 2004). Then, given the value of the distribution margin, the share of input usage in the distribution sector from Table 5, and the goods-markets clearing conditions for the three final goods, the value of the scale parameter of the distribution technology and the value of consumption allocations for the three goods are obtained.

Although the sectoral GDP value-added definition of this paper differs from that in Stockman and Tesar (1995), the definition of sectoral consumptions are identical in the two studies. ${ }^{25}$ Therefore, as estimated by Stockman and Tesar (1995), the elasticity of substitution between traded (composite) and nontraded consumption is set to 0.44 . Then, the planner's first order conditions for labor, consumption of nontraded goods, and consumption of imported goods obtain the labor share in the utility function, $\eta$; the share of nontraded consumption within the consumption aggregate, $\omega$; and the share of imports within the traded composite, $1-\nu$.

An estimation of the $\operatorname{VAR}(1)$ process for $\boldsymbol{\lambda}_{t} \equiv\left[\lambda_{x t}, \lambda_{n t}, \lambda_{m t}^{*}, \lambda_{n t}^{*}\right]$ is obtained by applying seemingly unrelated OLS with cross-country symmetry restrictions to a pairwise time-series of sectoral Solow residuals for the following countries: Canada, France, Germany, Italy, UK, and US, for which

\footnotetext{
${ }^{24}$ For checking the robustness of the results presented in Section 6 , the model is recalibrated for $\sigma=\epsilon_{x}=\epsilon_{d}=$ $\epsilon_{n}=2$. The corresponding parameter values are shown in Table 11.

${ }^{25}$ As in the present work, Stockman and Tesar (1995, footnote 6) define consumption of nondurable goods and consumption of services as traded and nontraded components of consumption, respectively. An alternative definition that bundles consumption by activity is also similar to the one used in the present work (see data Appendix).
} 
capital stock data is available. An average of the above pairwise estimates is presented in Table 8.

The parameters calibrated above define the benchmark model. To highlight the role of multisectoral inputs in investment and the role of distribution services, we recalibrate two variations of the model. In the first, $\phi=\alpha_{x}=1$ and $\alpha_{n}=0$; i.e., the two sectors utilize their own output for investment. Here, the model is recalibrated to match the remaining data ratios. The key changes occur in the share parameter for traded consumption aggregate and that of exportable consumption within that traded aggregate (see Table 7). A readjustment of investment inputs leaves excess traded inputs that are now reallocated towards consumption. Moreover, as investments no longer demand imports, excess imports are allocated towards the imported component of traded consumption. As a result, the traded consumption scale parameter $\omega$ increases from 0.065 to 0.12 , while the share of exportable consumption within the traded aggregate, $\nu$, reduces from 0.56 to 0.45 .

In the second variation, $\psi=0$; i.e., the distribution services are assumed away. For expositional convenience, further discussion of this recalibration exercise is postponed to Section 6.2.

\section{Quantitative results}

This section compares the moments generated by the benchmark model with the data moments discussed in Section 2. The results are first compared with the Stockman and Tesar (1995) (S\&T henceforth) results and a variation of the benchmark model in which, as in S\&T, sectors use their own as capital instead of multisectoral inputs in investments ( $M I I$ henceforth). The results from the benchmark model's version that abstracts from distribution services are also compared with. The intuition behind the key differences between the benchmark results and its alternatives are discussed in subsequent subsections.

The solution technique used throughout is linear-quadratic approximation and all businesscycle statistics are computed from 300 simulations of 300 periods each, after disregarding the first 200 periods of each simulation. The model generated data is HP-filtered exactly as in Section 2. All aggregate quantities in the data, discussed in Section 2, are at constant (base) prices, which 
implies that intersectoral relative prices too are constant across time at the base year level. Since results can be sensitive to the method of aggregation, ${ }^{26}$ all economywide aggregates in the model, to ensure consistency with the data, are constructed by using constant intersectoral relative prices.

Table 9 reports volatilities of (aggregate as well as sectoral) output, consumption, investment, employment, and volatilities of trade balance, terms of trade, relative price of nontraded goods, and real exchange rates. Domestic correlations are reported in the last part of the table. Table 10 reports cross-country correlations of aggregate as well as sectoral quantities. In both the tables, the first column (a) presents data moments discussed in Section 2. Results obtained from the benchmark model are presented in column (c), preceded by S\&T results in column (b) for a convenient contrast. $^{27}$ The next two columns (d) and (e) present results from the benchmark model's two variations (i) without MII and (ii) without distribution services, respectively.

In all columns of Table 9, volatilities of output, investment, and employment in the traded sector are higher than their nontraded counterparts, as in the data. Column (c) indicates that the benchmark model replicates the volatilities of output and investment reasonably well. The volatilities of employment are close to the lower bound of the data range as is the case with other models. Consumption volatilities fall much below the data, but all other versions fare equally badly. The model without MII reports (column (d)) a higher traded sector volatility of output, employment, and investment. While the first two are relative improvements, its traded sector investment volatility turns out to be too high. On the other hand, while S\&T volatilities of output, consumption and employment (column (b)) are similar to the benchmark, its investment volatilities are low; the benchmark model is closer to the data.

The volatilities of trade balance and relative prices are remarkably improved under the benchmark model. Relative to the S\&T and the model without MII, the benchmark volatility of trade balance is about three times, its volatility of terms of trade and relative price of nontraded goods is

\footnotetext{
${ }^{26}$ Kehoe and Ruhl (2008), for example, show that the comovement of terms of trade with GDP crucially depends on how the latter is constructed.

${ }^{27}$ The differences in S\&T results reported here and in their paper arise because (a) the shocks are different, (b) their simulation results are not filtered, and (c) all aggregates in S\&T paper are computed at current prices.
} 
about two to three times, and that of its real exchange rate is about twice. Once again, benchmark volatilities are much closer to the data. Yet, the real exchange rate volatility in the benchmark model falls below the data.

The benchmark model substantially outperforms its version without MII as well as S\&T model in replicating within country correlations. Specifically, its correlation of trade balance with output, as in the data, is significantly negative (-0.37) compared to the model without MII (-0.14) and S\&T (0.20). Similarly, its consumption correlation with output (0.87) is closest to the data compared with the other two (0.95). In S\&T and the benchmark's version without MII investment is perfectly correlated with output; the benchmark model lowers it, although only slightly (to 0.98). Finally, within country correlations of sectoral outputs, consumptions, investments, and employments are all improved in the benchmark model relative to the model without MII and the S\&T model.

What distinguishes the benchmark model most against its version without MII and S\&T is its relative ordering of cross-country correlation of output and consumption (see Table 10). Although cross-country correlation of aggregate output remains about the same across various versions $(0.41$ - 0.46), that of aggregate consumption is much reduced in the bench mark model (0.27) relative to its version without MII (0.41) and S\&T (0.70); sectoral consumption correlations are also lower than the other two. Investment correlations in the benchmark model are close to the data targets, whereas it is slightly higher in the model without MII and the S\&T model. The only relative shortcoming of the benchmark model is its cross-country correlation of traded sector's output and employment; in particular the latter exceeds the data upper bound. All models, however, underpredict nontraded output and employment correlations.

To summarize, the benchmark model markedly outperforms its own version without MII and the S\&T model in matching data volatilities of investments, trade balance, terms of trade, and real exchange rates. It comes closest to the data in replicating all within country correlations, and as in the data its cross-country consumption correlation falls much below that of output.

A comparison of the improvements by benchmark over its version without MII vis-à-vis improvements by benchmark over S\&T indicates that these are qualitatively similar. Below we first 
attempt to understand the underlying mechanism that aligns benchmark results (in contrast to the other two) with the data due to its inclusion of multisectoral investment composition.

\subsection{The role of multiple input investments}

An examination of impulse responses helps understand these results. Figure 2 shows the responses of output, consumption, investment, and employment under one standard deviation shock to the traded sector (i.e., exportable) productivity of country 1. Figure 3 repeats the same for a shock to the nontraded sector. In both figures, solid (broken) lines represent the benchmark (without MII) model, whereas darker (lighter) lines represent country 1 (2).

Under a traded sector shock, the most striking differences arise in the nontraded sector of country 1. While nontraded output, investment, and employment of country 1 fall in the model without MII, they all rise in the benchmark model. The reason is simple. When the exportable sector invests solely in its own good, a high relative demand for exportables drives labor from nontraded to exportable production. Moreover as shocks are persistent, future lower relative demand for nontraded output lowers its investment as well. In contrast, in the benchmark model, exportable sector's investment demand for nontraded goods raises its output, employment, and investment. A similar logic works for country 2's exportables' response, albeit quantitatively to a lesser degree; its output, investment, and employment rise on impact due to country 1's investment demand for imports; the responses are almost flat in the model without MII. This explains why internal correlations of sectoral outputs, employments, and investments turn to be positive (instead of close to zero or negative in model without MII), and also why traded sector's cross-country correlations of output and employment rise.

Nontraded consumption response of country 1 also provides a stark contrast. In the benchmark model, a higher exportable sector investment demands more of its nontraded goods lowering its consumption on impact. This helps reduce within country traded-nontraded consumption correlations. Also, because of a fall in its nontraded component, aggregate consumption rise is muted in the benchmark model relative to its version without MII. The consumption response in country 2, 
though quantitatively smaller, is qualitatively similar to that in country 1 . In sum, both countries' consumption rises are inhibited in the benchmark model. ${ }^{28}$

Finally, notice that the aggregate output in country 1 does not differ much. Essentially, in country 1 the rise in nontraded output in the benchmark model is offset by a fall in its traded output. In country 2 aggregate output slightly rises due to a rise in its traded component, thus helping a slight rise in cross-country correlations.

Consider now a positive productivity shock in the nontraded sector of country 1 (Figure 3). As under traded sector shock, the most striking differences now are in the production and employment in the other sector, i.e., the exportables. Both move positively with their nontraded counterparts in contrast to their negative comovement in the model without MII. In the benchmark model, a higher investment demand for exportables from the nontraded sector induces a higher output and employment in the former. This again helps align model's domestic correlations with the data. Similarly, with a higher nontraded sector's investment demand for imports, country 2's exportable output is higher in the benchmark model. A part of the increased demand for imports is met by cutting country 2's traded consumption as well as its traded sector investment. As a result, cross-country comovements of traded consumption and investment are reversed in the benchmark model, helping reduce the correlation of their aggregates as well.

Since nontraded sector invests only partly on its own output, a larger part can be absorbed as consumption in the benchmark model relative to its version without MII. The consumption of traded goods remains almost identical under the two specifications. Therefore, unlike under traded sector shock, aggregate consumption of country 1 is higher in the benchmark model (compare Figure 2(d) with Figure 3(d)). The aggregate consumption of country 2 hardly changes. This further helps in uncoupling cross-country consumption comovements.

Once again, as under traded sector shock, the aggregate output response for both countries is almost identical under the two models. In country 1 a relatively higher exportable output is

\footnotetext{
${ }^{28}$ Consumption comovement across the two countries appears more aligned under the traded sector shock. It can therefore be conjectured that the explanation for a lower crosscountry consumption correlation in the benchmark model mainly lies with the nontraded shocks.
} 
compensated by a relatively lower nontraded output. That is why cross-country output correlation rises only slightly to 0.45 in the benchmark from 0.41 in its version without MII.

\subsection{The role of distribution services}

It is evident that the improvements that benchmark achieves over its version without MII are further pronounced when the former is compared with the $\mathrm{S} \& \mathrm{~T}$ results. To explore whether this is due to the inclusion of distribution services in the benchmark model, column (e) presents results from the benchmark's version without distribution services while retaining the multisectoral composition of investments. The results within square brackets relate to the model without distribution services in which the relative sizes of sectoral outputs are identical to the benchmark. However, then the model fails to match consumption expenditures on traded and nontraded goods. The values outside relate to the model without distribution in which as in S\&T distribution services are included in the traded sector that allows relative consumption expenditures to stay as in the benchmark; below this is disussed first.

Comparing column (e) with (c) in Table 9 shows that the volatilities are similar except slightly higher values for aggregate output and traded consumption. Within country correlations are similar except for sectoral consumptions and investments; it underpredicts the former and overpredicts the latter and fares worse on both counts. Also, trade balance is less countercyclical. Cross-country correlations in Table 10 are hardly different from their benchmark counterparts: only the correlation of traded sector output and consumption is slightly lower, and that of nontraded employment is higher.

Why does the role of distribution services appear to be marginal? It helps to first understand the calibration exercise. In the benchmark model, traded output is only about $44 \%$ of nontraded output, whereas traded consumption is about $62 \%$ of nontraded consumption. After duly accounting for investment expenditure shares, the disproportionate traded consumption expenditure at the retail level relative to its own output is reconciled by its embodied nontraded distribution services. To be consistent with the observed consumption expenditures, abstracting from distribution 
services therefore requires a counterfactual reclassification of sectoral outputs: the nontraded component that delivers traded consumption at the retail level now counts as part of the traded output precisely as in $S E T$. A rebalancing then raises the size of exportable GDP to $72 \%$ of the nontraded GDP. This in turn requires recalibrating sectoral input shares for the two sectoral investments as well. Accordingly, the model is recalibrated to match observed investment input expenditures, export/GDP ratio, and traded to nontraded consumption (see Table 7). Bundling distribution costs with exportable consumption expenditure lowers the share of imports in traded consumption to $25 \%(\omega=0.75)$ from $44 \%$ under the benchmark $(\omega=0.56)$. Another change occurs in the elasticity of substitution between traded and nontraded consumption; it drops from 0.44 in the benchmark model to $0.33 .^{29}$

Thus, the higher output volatility in the model without distribution is explained by its higher relative size of the traded sector and the fact that the traded sector is more volatile than the nontraded sector. A lower countercyclicality of trade balance and a lower cross-country correlation of traded consumption follow from a home bias in exportables' consumption. The rest of the results are explained below with the help of impulse responses.

Figures 4 and 5 compare impulse responses of output, consumption, investment, and employment under traded and nontraded shocks, respectively. Again, darker (lighter) line represents country 1 (2); solid (broken) line represents the benchmark model (without distribution).

Figure 4 shows that the traded consumption in country 1 rises relatively more in the model without distribution because fixed-proportions bundling with nontraded distribution services is no longer required, thus increasing the volatility of traded consumption (mostly exportables due to home bias). A larger traded consumption raises consumption demand for nontraded goods. In addition, the recalibrated traded sector in the model without distribution invests a larger share on nontraded goods. Lastly, traded sector is larger in the model without distribution. All three raise nontraded output and employment in country 1 . The nontraded consumption still falls but less than

\footnotetext{
${ }^{29}$ However, the results are almost identical if the elasticity is allowed to remain the same at 0.44 , and instead the share parameter $\omega$ is recalibrated (from 0.065 to 0.13 ).
} 
in the benchmark model. Overall, the negative comovement of the two consumption components is more pronounced thus lowering their within country correlation. On the other hand, nontraded output and investment comovements with those of exportables are more pronounced, raising their within country correlations. A higher home-bias in the model without distribution demands less of importables. Nontraded output in country 2 rises slightly. Increases in nontraded outputs in both countries are brought about by even larger increases in their employment which helps explain their higher cross-country correlation.

Under a nontraded positive shock (see Figure 5), a higher nontraded output in the model without distribution does not command as high a rise in traded consumption as in the benchmark model. The savings in exportables can rather be used for its own investment. Under both shocks, therefore, within country cross-sectoral correlation of consumption falls while that of investment rises. In country 1, without distribution services, all non traded aggregates i.e., consumption, output, and investment rise less on impact. A lower nontraded output in country 1 requires a much smaller rise in its employment, which now comoves less negatively with country 2's nontraded employment, thus again helping raise their cross-country correlation.

The result that an explicit inclusion of distribution services in the model does not matter much is robust to an alternative calibration exercise in which the benchmark sectoral GDP definitions are retained, i.e., distribution services are measured as part of the nontraded sector and therefore the relative size of its GDP is left at 2.25. When no longer required to deliver traded consumption, distribution services have to be absorbed as nontraded consumption. The ratio of traded to nontraded expenditure falls to 0.34 from 0.62 in the benchmark model (and as in the data). A recalibration obtains a much lower share parameter $(\omega=0.035$ relative to 0.065 under the benchmark) of traded consumption. The results, as presented within square brackets in column (e), are even closer to the benchmark results. For example the GDP - trade balance correlation is -0.34 (-0.37 in the benchmark), cross country output correlation is 0.43 (0.45 in the benchmark) and that of consumption is 0.28 (0.27 in the benchmark).

Finally, notwithstanding the equivalence of the results discussed here, it is worth reiterating 
that the model with distribution services is the only correct specification that is consistent not only with sectoral classifications (of traded and nontraded goods) but also with the relative consumption expenditure shares.

\subsection{Benchmark vis-à-vis S\&T}

In principle, the benchmark model reduces to S\&T model after dropping distribution services and multiple-input investments. Yet, while removing MII from the benchmark model raises the crosscountry consumption correlation from 0.27 to 0.41 , it rises to as high as 0.70 in S\&T. Since an explicit incorporation of distribution costs does not seem to matter much, what explains this scale of benchmark's improvement over the S\&T?

The key once again lies in the calibration exercises. While in S\&T's calibration the inclusion of hospitality industry and distribution services in the traded sector makes its size equal nontraded sector's, the relative size of the latter in the benchmark model (and this paper's version without MII) is 2.25. This substantially enhances differences between with and without MII when applied to benchmark vis-à-vis S\&T. If instead S\&T definition of sectoral outputs is adopted and distribution services are subsumed within exportable consumption, the nontraded sector still remains relatively (about 1.4 times) larger. Moreover, while S\&T's calibration finds equal shares of imports and exportables in the traded consumption composite, with the data used in this paper a similar calibration indicates a substantial (3 to 1) home bias. A larger size of nontraded sector and home bias within traded composite, both inhibit consumption sharing across countries in this paper.

\subsection{Model performance under alternative specifications}

This section examines whether the improvements gained by the benchmark model over its competing versions are robust to (a) a higher elasticity of substitution between exportables and importables, and (b) an alternative specification of productivity shocks. 


\subsubsection{A higher trade elasticity}

The results discussed earlier are based on a unit elasticity of substitution between exportables and importables in consumption, as well as in production of capital goods. However, there is no clear consensus on the magnitude of trade elasticities. While micro studies pose it to be as high as 4, in macro literature it is found anywhere between 0.5 - 2. Corsetti, Dedola, and Leduc (2008) have shown that a low trade elasticity (of 0.85 in their paper) helps in inhibiting cross-country risk sharing. Since this paper claims that an accurate accounting of investment composition is the key to the results, its validity for a higher value of trade elasticity needs to be checked. To do so, the benchmark model and its variations are recalibrated after setting $\sigma=\epsilon=-0.5$, which implies an elasticity of substitution equal to 2 between importables and exportables, across all traded composites. The recalibrated parameter values are shown in Table 11.

Columns (a) - (c) of Tables 13 and 14 present the results. Comparing these numbers with their counterparts in Table 9 and Table 10 demonstrates that, across all model variations, most noticeable changes occur in the volatility of trade balance, terms of trade, and the cyclicality of trade balance. With a higher trade elasticity, more substitution occurs between importables and exportables in equilibrium, at lower terms of trade movement. Thus, while the trade balance is more volatile as the elasticity rises, the volatility of terms of trade falls. Also, with a higher elasticity, a terms of trade depreciation due to a higher output of exportables implies a relatively higher export and less import. As a result, trade balance is less countercyclical.

It is worth noting that in the model without MII, where sectors utilize their own output for investment, a change in trade elasticity does not directly affect investment composition. Yet the benchmark model continues to outperform its version without MII, as in the unit elasticity case. Again, the model without distribution does not look much different from the benchmark, except for a lower volatility of real exchange rate and a lower countercyclicality of trade balance, as under unit trade elasticity. 


\subsubsection{Shocks with no spillovers and no sectoral correlations}

As discussed in Section 5, the shocks used for simulation are an average of pairwise estimates from Canada, France, Germany, Italy, the UK, and the US. ${ }^{30}$ However, since the estimates depend on the subset of countries and/or their aggregates, a question arises as to what extent this paper's results hinge on the adopted shock estimates.

To highlight (co)movements endogenous to the model, it is simulated under an assumed simple shock structure given in Table 12. First, there are no spillovers, either across countries or sectors. Second, to isolate the source of within-country comovements, sectoral shocks are left uncorrelated. All sectoral autocorrelations and variances are set symmetrically to about an average of the two sectors. Finally, for both sectoral shocks, cross-country correlations are set symmetrically to 0.4 , which is about an average of their counterparts in estimated shocks (see Table 8). ${ }^{31}$

The results are presented in columns (d) - (f) of Tables 13 and 14. As with estimated shocks, the volatilities of trade balance and relative prices are substantially higher in the benchmark model, relative to its version without MII; trade balance is more countercyclical; within-country correlations are much closer to the data; and cross-country output correlations exceed that of consumption. The results conclusively demonstrate that it is the investment composition that matters.

\section{Concluding Remarks}

This paper incorporates observed compositional shares of investment expenditures into an otherwise standard two-country complete-markets international business cycle model as in Stockman and

\footnotetext{
${ }^{30}$ These estimates are qualitatively similar to those in Stockman and Tesar (1995). In a previous version of this paper (see Ovideo and Singh (2011)), the two data counterparts of the model economies are US and an aggregate of Canada, France, Germnay, Italy and the UK. However, the shocks thus estimated exhibit very low persistence; the persistence in the nontraded sector is even slightly negative. The estimates also exhibit negative cross-country spillovers. These features are at odds with shocks previously estimated and used by other researchers. Yet the benchmark model continues to outperform its version without MII (see Table 8) in obtaining (i) a higher volatility of trade balance, terms of trade, and real exchange rate; and (ii) resolving the quantity anomaly. Domestic correlations are not studied in this paper.

${ }^{31}$ Setting cross-counry shock correlations to zero obtains very low (positive) cross-country correlation of output; consumption correlation turns out to be low as well, but negative.
} 
Tesar (1995). In the model presented in this study, not only consumption but also investments comprise exportables, imports, and nontraded goods. Another departure from Stockman and Tesar (1995) is that distribution services (Retail and wholesale services; Transportation services) are defined in the nontraded sector and are explicitly incorporated into the model $\grave{a}$ la Burstein, Neves, and Rebelo (2003).

The model so calibrated outperforms the model in which sectoral investments utilize their own outputs. It obtains higher volatilities of trade balance, terms of trade, relative prices of nontraded goods, real exchange rates, and overall comes closer to the data. Trade balance as in the data is significantly countercyclical. Within country comovements of sectoral aggregates are remarkably closer to the data and the comovements of output with consumption, investment, and employment are also improved. Finally, cross-country consumption correlation lies sufficiently below that of output: the quantity anomaly does not arise in the model with multisectoral composition of investments.

The standard nomenclature for sectoral aggregation calls for distribution services to be in the nontraded sector and indeed the model performs the best when distribution costs are explicit in the model. However, whether distribution services are explicitly featured as technology or, somewhat counterfactually, implicitly embedded in preferences is not critical to the results as long as a careful output-absorption calibration is exercised. The main lesson that emerges is that aligning model with data primarily requires recognizing that capital goods are produced using inputs of exportable, importable, and nontraded goods, so that any changes in the production and absorption possibilities of one directly impacts those of the others.

A major shortcoming of complete markets assumption in this study is that the marginal rate of consumption substitution across countries is perfectly correlated with the real exchange rate, contrary to its low and negative correlation in the data as first noted by Backus and Smith (1993). In addition, models with perfect risk sharing generate lower price volatilities than in the data. Research has shown that the performance of relative price movements and consumption-price comovements 
improve under incomplete markets. ${ }^{32}$ Insofar as intersectoral investment demands increase relative price volatilities as shown in this paper, and also uncouple relative price movements from their relative consumption demands, introducing multisectoral composition of investments under incomplete markets will likely help towards the resolution of Backus-Smith puzzle. A formal check of this conjecture is left for future work.

\section{Appendix: Data}

Gross Domestic Product For sectoral traded and non-traded GDP value-added aggregation, 60-industry data provided by Groningen Growth Development Center (GGDC) is utilized. The industries are grouped according to the International Standard Industrial Classification (ISIC) revision 3, which is consistent with the decomposition of industries in most of the OECD statistics. The Traded aggregate of GDP includes Agriculture, Forestry, Fishing, Mining and quarrying, and Manufacturing. Manufacturing includes Food, drink \& tobacco; Textiles; Clothing; Leather and footwear; Wood \& products of wood and cork; Pulp, paper \& paper products; Printing \& publishing; Mineral oil refining, coke \& nuclear fuel; Chemicals; Rubber \& plastics; Non-metallic mineral products; Basic metals; Fabricated metal products; Mechanical engineering; Office machinery; Insulated wire; Other electrical machinery and apparatus; Electronic valves and tubes; Telecommunication equipment; Radio and television receivers; Scientific instruments; Other instruments; Motor vehicles; Building and repairing of ships and boats; Aircraft and spacecraft; Railroad equipment and transport equipment nec; Furniture, miscellaneous manufacturing; recycling.

The non-traded GDP aggregate includes Electricity, gas and water supply; Construction; Sale, Maintenance and repair of motor vehicles and motorcycles including retail sale of automotive fuel; Wholesale trade and commission trade, except of motor vehicles and motorcycles; Retail trade, except of motor vehicles and motorcycles; Repair of personal and household goods; Hotels \& catering; Inland transport; Water transport; Air transport; Supporting and auxiliary transport activities;

\footnotetext{
${ }^{32}$ See, for example, Corsetti, Dedola, and Leduc (2008).
} 
activities of travel agencies; Communications; Financial intermediation, except insurance and pension funding; Insurance and pension funding, except compulsory social security; Activities auxiliary to financial intermediation; Real estate activities; Renting of machinery and equipment; Computer and related activities; Research and development; Legal, technical and advertising; Other business activities; Public administration and defence including compulsory social security; Education; Health and social work; Other community, social and personal services; Private households with employed persons.

The industrywise data includes value added at current prices as well as the industrywise (price) deflator growth rates. The time series (1979-2004) of sectoral and aggregate real GDP at base year (1995) prices are constructed by using these deflators. A longer time series (1955-2005) of aggregate GDP at constant base year prices is also obtained from OECD National Accounts (see Table 1).

Consumption Sectorwise Consumption data at constant prices is obtained from detailed tables provided under National Accounts of OECD Statistics 1970-2004. The traded aggregate of consumption includes Food and non-alcoholic beverages; Alcoholic beverages, tobacco and narcotics; Clothing and footwear; Furniture and furnishings, carpets and other floor coverings; Household textiles; Household appliances; Glassware, tableware and household utensils; Tools and equipment for house and garden; Medical products, appliances and equipment; Audio-visual, photographic and information processing equipment. The non-traded consumption aggregate includes Housing, water, electricity, gas and other fuels; Goods and services for routine household maintenance; Outpatient services; Hospital services; Operation of personal transport equipment; Transport services; Communications; Other recreational items and equipment, gardens and pets; Recreational and cultural services; Newspapers, books and stationery; Package holidays; Education; Restaurants and hotels; Miscellaneous goods and services. An alternative way to distinguish between traded and non-traded consumption is as in Stockman and Tesar (1995): traded consumption is proxied by the private final consumption of non-durable goods, while the private final consumption of services is used for non-traded consumption. The second moments of sectoral aggregates by both definitions 
however are very close to each other. The total consumption aggregate is the sum of the two components.

Investment and employment Sectoral investment and employment aggregates follow the GDP classification. Industrywise Total Annual Hours Worked provided by GGDC is utilized for employment aggregates. For investment aggregates, Gross Fixed Capital Formation provided by OECD STAN at current prices is used. The sectoral series are deflated by GDP deflator assuming that, as in the data, investments utilize inputs from both traded and nontraded sectors.

Solow residuals This exercise utilizes sectoral output and employment data from GGDC and Gross Capital Stock at constant prices from OECD Structural Analysis Network (STAN); the latter is available only for a limited number of countries: within G-7 it is not available for the US and Japan; for Germany it is only partially (1991-2003) available. The GDP sectoral classification is followed for sectoral aggregation of capital stock. The data for the US is obtained from the Bureau of Labor Statistics (BLS) which decomposes assets into Farm, Manufacturing, and Non-farm Nonmanufacturing sectors. While assets relating to farm and manufacturing constitute the traded sector capital, nonfarm nonmanufacturing capital stock corresponds to the non-traded sector.

\section{Appendix: Solution to the planner's problem and steady state allocations}

Below, we solve the planner's problem in order to derive symmetric steady states. The planner's problem is to maximize $W_{1}+W_{2}$, where $W_{1}$ and $W_{2}$ denote the present discounted value of the representative agents utility in country 1 and 2 respectively, where

$$
W \equiv \sum_{t=0}^{\infty} \beta^{t} U\left(c^{T}\left(c_{x}, c_{m}\right), c_{n},\left(1-h_{x}-h_{n}\right)\right) .
$$

where

$$
c^{T}\left(c_{x}, c_{m}\right)=\left[\nu c_{x}^{-\sigma}+(1-\nu) c_{m}^{-\sigma}\right]^{-\frac{1}{\sigma}}
$$


The set of constraints each country faces is

$$
\begin{aligned}
c_{x t}+\sum_{i \equiv x, n, d} x_{i t}+e_{x t} & =F^{x}\left(\lambda_{x t}, k_{x t}, h_{x}\right), \\
c_{n t}+\sum_{i \equiv x, n, d} n_{i t} & =F^{n}\left(\lambda_{n t}, k_{n t}, h_{n t}\right), \\
\left(1-\delta_{x}\right) k_{x t}+s_{x t} & =k_{x t+1}, \\
\left(1-\delta_{n}\right) k_{n t}+s_{n t} & =k_{n t+1},
\end{aligned}
$$

and the distribution constraint:

$$
\psi\left(c_{x t}+c_{m t}\right)=s_{d t} .
$$

Notice that at a symmetric steady state $e_{x}=e_{m}^{*}$. Since the main interest here is to derive equations that obtain steady states, it suffices, as will become clear below, to consider only country 1's component of the Lagrangian of the social planner. Letting the planner's Lagrangian be $U=U_{1}$ $+U_{2}$. where $U_{1}$ denotes country 1's component, after appropriate substitutions, $U_{1}$ can be written as (the treatment of $U_{2}$ is implicit):

$$
\begin{aligned}
U_{1}= & \sum_{t=0}^{\infty} \beta^{t} U\left(\begin{array}{c}
\left.\nu\left(F^{x}\left(\lambda_{x t}, k_{x t}, h_{x t}\right)-\sum_{i \equiv x, n, d} x_{i t}-e_{x t}\right)^{-\sigma}+(1-\nu)\left(e_{m t}^{*}-\sum_{i \equiv x, n, d} m_{i t}\right)^{-\sigma}\right]^{-\frac{1}{\sigma}} \\
F^{n}\left(\lambda_{n t}, k_{n t}, h_{n}\right)-\sum_{i \equiv x, n, d} n_{i t}, \\
\left(1-h_{x t}-h_{n t}\right)
\end{array}\right)+ \\
& \sum_{t=0}^{\infty} \beta^{t} q_{x t}\left(\left(1-\delta_{x}\right) k_{x t}+s_{x t}-k_{x t+1}\right) \quad \\
& \sum_{t=0}^{\infty} \beta^{t} q_{n t}\left(\left(1-\delta_{n}\right) k_{n t}+s_{n t}-k_{n t+1}\right)+\sum_{i=0}^{\infty} \beta^{t} q_{d t}\left(\begin{array}{c}
\left.s_{d t}-\psi\left(\lambda_{x t}^{x}, k_{x t}, h_{x}\right)-\sum_{i \equiv x, n, d} x_{i t}-e_{x t}\right) \\
-\psi\left(e_{m t}^{*}-\sum_{i \equiv x, n, d} m_{i t}\right)
\end{array}\right)
\end{aligned}
$$

where $q$ s denote lagrangian multipliers on their respective constraints. The planner's decision variables are for country 1 are: $h_{x}, h_{n}$, and $j_{i}$ for $j=x, m, n$ and $i=x, n, d ; e_{x}$ and $e_{m}^{*}$ are decisions 
that affect both countries. Using the functional forms for $s_{i} \mathrm{~s}$, the FOCs are:

$$
\begin{array}{ll}
x_{x t}: & U_{1 t} c_{x}^{T}\left(c_{x t}, c_{m t}\right)=q_{x t} \frac{\partial s_{x t}}{\partial x_{x t}}+\psi q_{d t}, \\
m_{x t}: & U_{1 t} c_{m}^{T}\left(c_{x t}, c_{m t}\right)=q_{x t} \frac{\partial s_{x t}}{\partial m_{x t}}+\psi q_{d t}, \\
n_{x t}: & U_{2 t}=q_{x t}\left(1-\alpha_{x}\right) \frac{s_{x t}}{n_{x t}}, \\
x_{n t} \quad: \quad U_{1 t} c_{x}^{T}\left(c_{x t}, c_{m t}\right)=q_{n t} \frac{\partial s_{n t}}{\partial x_{n t}}+\psi q_{d t}, \\
m_{n t}: \quad U_{1 t} c_{m}^{T}\left(c_{x t}, c_{m t}\right)=q_{n t} \frac{\partial s_{n t}}{\partial m_{n t}}+\psi q_{d t}, \\
n_{n t}: \quad U_{2 t}=q_{n t}\left(1-\alpha_{n}\right) \frac{s_{n t}}{n_{n t}}, \\
x_{d t}: \quad U_{1 t} c_{x}^{T}\left(c_{x t}, c_{m t}\right)=q_{d t} \frac{\partial s_{d t}}{\partial x_{d t}}+\psi q_{d t}, \\
m_{d t}: \quad U_{1 t} c_{m}^{T}\left(c_{x t}, c_{m t}\right)=q_{d t} \frac{\partial s_{d t}}{\partial m_{d t}}+\psi q_{d t}, \\
n_{d t}: \quad U_{2 t}=q_{d t}\left(1-\alpha_{d}\right) \frac{s_{d t}}{n_{d t}} .
\end{array}
$$

Note that

$$
\begin{aligned}
c_{x}^{T}\left(c_{x}, c_{m}\right) & =\nu\left[\frac{c^{T}\left(c_{x}, c_{m}\right)}{c_{x}}\right]^{1+\sigma} ; c_{m}^{T}\left(c_{x}, c_{m}\right)=(1-\nu)\left[\frac{c^{T}\left(c_{x}, c_{m}\right)}{c_{m}}\right]^{1+\sigma} ; \\
\frac{\partial s_{i t}}{\partial x_{i t}} & =\frac{\alpha_{i} s_{i t}}{x_{i t}\left(1+\left(\frac{1-\mu_{i}}{\mu_{i}}\right)\left(\frac{m_{i t}}{x_{i t}}\right)^{-\epsilon_{\iota}}\right)} ; \frac{\partial s_{i t}}{\partial m_{i t}}=\frac{\alpha_{i t}\left(1+\left(\frac{\mu}{1-\mu}\right)\left(\frac{x_{i t}}{m_{i t}}\right)^{-\epsilon_{\iota}}\right)}{\left.m_{i t}\right)}
\end{aligned}
$$

The FOC with respect to hours worked are:

$$
\begin{aligned}
& h_{x}:\left[U_{1 t} c_{x}^{T}\left(c_{x t}, c_{m t}\right)-\psi q_{d t}\right] F_{h t}^{x}=U_{3 t}, \\
& h_{n}: \quad U_{2 t} F_{h t}^{n}=U_{3 t} .
\end{aligned}
$$

The FOCs with respect to $t+1$ capital stocks yield

$$
\begin{array}{r}
\beta q_{x t+1}\left(1-\delta_{x}\right)-q_{x t}+\beta U_{1, t+1} c_{x}^{T}\left(c_{x t+1}, c_{m t+1}\right) F_{k, t+1}^{x}-\beta q_{d t+1} \psi F_{k, t+1}^{x}=0 \\
\beta q_{n t+1}\left(1-\delta_{n}\right)-q_{n t}+\beta U_{2, t+1} F_{k, t+1}^{n}=0 .
\end{array}
$$

The FOC with respect to $e_{x t}$ is

$$
U_{1 t} c_{x}^{T}\left(c_{x t}, c_{m t}\right)-\psi q_{d t}=U_{1 t}^{*} c_{m}^{T}\left(c_{x t}, c_{m t}\right)-\psi q_{d t}^{*}
$$


Equations (17) - (31), (12) - (16) along with $c_{x}^{*}=c_{m}, c_{m}^{*}=c_{x}, q_{d}=q_{d}^{*}$ and $e_{m}^{*}=e_{x}$ (by symmetry) are sufficient to obtain the steady state values for all variables of country 1 ; by symmetry, country 2's values are identical.

Simplification Equations (29) and (30) give

$$
\begin{aligned}
U_{1} c_{x}^{T}\left(c_{x}, c_{m}\right)-q_{d} \psi & =\frac{q_{x}}{F_{k}^{x}}\left(r+\delta_{x}\right), \\
U_{2} & =\frac{q_{n}}{F_{k}^{n}}\left(r+\delta_{n}\right) .
\end{aligned}
$$

Next, (31) becomes

$$
\frac{c_{m}}{c_{x}}=\left(\frac{1-\nu}{\nu}\right)^{\frac{1}{1+\sigma}} .
$$

Using (34), (32) and (33), steady state versions of equations (17) - (25) are

$$
\begin{aligned}
& x_{x}: \quad F_{k}^{x} \frac{\partial s_{x}}{\partial x_{x}}=r+\delta_{x}, \\
& m_{x}: \quad F_{k}^{x} \frac{\partial s_{x}}{\partial m_{x}}=r+\delta_{x}, \\
& n_{x} \quad: \quad F_{k}^{n} \frac{q_{x}}{q_{n}}\left(1-\alpha_{x}\right) \frac{s_{x}}{n_{x}}=r+\delta_{n}, \\
& x_{n} \quad: \quad F_{k}^{x} \frac{q_{n}}{q_{x}} \frac{\partial s_{n}}{\partial x_{n}}=r+\delta_{x}, \\
& m_{n} \quad: \quad F_{k}^{x} \frac{q_{n}}{q_{x}} \frac{\partial s_{n}}{\partial m_{n}}=r+\delta_{x}, \\
& n_{n} \quad: \quad F_{k}^{n}\left(1-\alpha_{n}\right) \frac{s_{n}}{n_{n}}=r+\delta_{n}, \\
& x_{d} \quad: \quad F_{k}^{x} \frac{q_{d}}{q_{x}} \frac{\partial s_{d}}{\partial x_{d}}=r+\delta_{x}, \\
& m_{d} \quad: \quad F_{k}^{x} \frac{q_{d}}{q_{x}} \frac{\partial s_{d}}{\partial m_{d}}=r+\delta_{x}, \\
& n_{d} \quad: \quad F_{k}^{n} \frac{q_{d}}{q_{n}}\left(1-\alpha_{d}\right) \frac{s_{d}}{n_{d}}=r+\delta_{n} .
\end{aligned}
$$

Steady state values Below we stack all equations that will be solved simultaneously for obtaining the steady state values. Using (32) and (33) with functional forms for $F^{i} \mathrm{~s},(27)$ and (28) gets

$$
\begin{aligned}
& h_{x}: q_{x}\left(r+\delta_{x}\right) \frac{1-\theta_{x}}{\theta_{x}} \frac{k_{x}}{h_{x}}=U_{3}, \\
& h_{n}: q_{n}\left(r+\delta_{n}\right) \frac{1-\theta_{n}}{\theta_{n}} \frac{k_{n}}{h_{n}}=U_{3} .
\end{aligned}
$$


The expressions for $q_{x}$ and $q_{n}$ directly follow from (32) and (33):

$$
\begin{aligned}
q_{x} & =\frac{U_{1} c_{x}^{T}\left(c_{x}, c_{m}\right)-\psi q_{d}}{r+\delta_{x}} F_{k}^{x}, \\
q_{n} & =\frac{F_{k}^{n} U_{2}}{r+\delta_{n}} .
\end{aligned}
$$

Further, in steady state:

$$
k_{x}=\frac{s_{x}}{\delta_{x}}, \text { and } \quad k_{n}=\frac{s_{n}}{\delta_{n}} .
$$

Include (34):

$$
\frac{c_{m}}{c_{x}}=\left(\frac{1-\nu}{\nu}\right)^{\frac{1}{1+\sigma}}
$$

The distribution constraint:

$$
\psi c_{x}\left(1+\left(\frac{1-\nu}{\nu}\right)^{\frac{1}{1+\sigma}}\right)=s_{d}
$$

Resource constraints:

$$
\begin{aligned}
& F^{x}\left(\lambda_{x}, k_{x}, h_{x}\right)=c_{x}+c_{m}+\sum_{i=x, n, d} x_{i}+\sum_{i=x, n, d} m_{i} \\
& F^{n}\left(\lambda_{n}, k_{n}, h_{n}\right)=c_{n}+\sum_{i=x, n, d} n_{i}
\end{aligned}
$$

Next 9 equations follow from (35) - (43):;

$$
\begin{aligned}
& \frac{x_{i}}{m_{i}}=\left(\frac{\mu_{i}}{1-\mu_{i}}\right)^{\frac{1}{1+\epsilon_{i}}} \quad i=x, n, d \\
& x_{x}: \quad F_{k}^{x} \frac{\alpha_{x} s_{x}}{x_{x}+m_{x}}=r+\delta_{x} \\
& n_{x}: \quad F_{k}^{n} \frac{q_{x}}{q_{n}}\left(1-\alpha_{x}\right) \frac{s_{x}}{n_{x}}=r+\delta_{n} \\
& x_{n} \quad: \quad F_{k}^{x} \frac{q_{n}}{q_{x}} \frac{\alpha_{n} s_{n}}{x_{n}+m_{n}}=r+\delta_{x} \\
& n_{n} \quad: \quad F_{k}^{n}\left(1-\alpha_{n}\right) \frac{s_{n}}{n_{n}}=r+\delta_{n} \\
& x_{d} \quad: \quad F_{k}^{x} \frac{q_{d}}{q_{x}} \frac{\alpha_{d} s_{d}}{x_{d}+m_{d}}=r+\delta_{x} \\
& n_{d} \quad: \quad F_{k}^{n} \frac{q_{d}}{q_{n}}\left(1-\alpha_{d}\right) \frac{s_{d}}{n_{d}}=r+\delta_{n}
\end{aligned}
$$

There are 19 equations in 19 unknowns: $h_{x}, h_{n}$, and $j_{i}$ for $i=x, m, n$ and $j=x, n, d ; k_{n}, k_{x}, c_{x}, c_{m}, c_{n}$, $q_{x}, q_{n}$, and $q_{d}$. 


\subsection{Relative prices in equilibrium}

In a decentralized competitive equilibrium, the two investment goods, the distribution services as well as the three final goods have their own price in each country. Moreover, there is a distinction between the price of exportable and importable goods at the producer level and their corresponding prices at the consumer level. The price of exportable goods at the producer level in country 1 is the price of importable goods at the producer level in country 2 and viceversa. As the quantitative analysis below refers to some of these prices, particularly the consumer price index and the real exchange rate, these prices are described below.

The price of exportables and importables at the producer level are $\bar{p}_{x}$ and $\bar{p}_{m}$; at the retail level, after utilizing distribution services, the respective consumer prices are $p_{x}=\bar{p}_{x}+\psi p_{d}$ and $p_{m}=\bar{p}_{m}+\psi p_{d}$, where $p_{d}$ is the price of distribution services; $p_{n}$ is the price of nontradable goods. The price of investment goods to be employed in the tradable sector is $p_{x}^{k}$ and the price of investment goods to be used in the nontradable sector is $p_{n}^{k}$. The consumer price index in country 1 is defined in the standard way: it is the minimum expense required to obtain $C\left(c_{x}, x_{m}, c_{n}\right)=1$ given $p_{x}, p_{m}$, and $p_{n}$. Let $P$ denote the consumer price index in country 1 ; by assuming that the nominal exchange rate is equal to 1 , the real exchange rate is $\mathrm{RER}=P^{*} / P$.

The expression for relative prices are as derived below. First, the relative price of non-traded goods is

$$
\frac{p_{n}}{\bar{p}_{x}}=\frac{F_{h}^{x}}{F_{h}^{n}}=\frac{1-\theta_{x}}{1-\theta_{n}} \frac{y_{x}}{y_{n}} \frac{h_{n}}{h_{x}},
$$

since wages across the two sectors must be equalized. Similarly, as intermediate capital goods producers and distribution services utilize exports as well as imports, their relative prices (terms of trade) must follow

$$
\frac{\bar{p}_{m}}{\bar{p}_{x}}=\frac{1-\mu_{j}}{\mu_{j}}\left(\frac{x_{j}}{m_{j}}\right)^{1+\epsilon_{j}} \text { for } j=x, n, d
$$

The marginal value of a unit of exportable good in the distribution sector must equal its price. 
Therefore, the relative price of distribution services is

$$
\frac{p_{d}}{\bar{p}_{x}}=\left(\frac{d s_{d}}{d x_{d}}\right)^{-1}=\frac{\alpha_{d} s_{d}}{x_{d}\left(1+\frac{1-\mu_{d}}{\mu_{d}}\left(\frac{x_{d}}{m_{d}}\right)^{-\epsilon_{d}}\right)}
$$

The retail prices of exportables and importables are obtained in a straightforward manner:

$$
\begin{aligned}
p_{x} & =\bar{p}_{x}+\psi p_{d} \\
p_{m} & =\bar{p}_{m}+\psi p_{d}
\end{aligned}
$$

Finally, the Consumer Price Index is derived using the consumption index and the relative prices of its components as:

$$
\begin{aligned}
P= & {\left[\begin{array}{c}
\omega^{\frac{1}{1+\rho}}\left(\left[\nu^{\frac{1}{1+\sigma}} p_{x}^{\frac{\sigma}{1+\sigma}}+(1-\nu)^{\frac{1}{1+\sigma}} p_{m}^{\frac{\sigma}{1+\sigma}}\right]^{\frac{1+\sigma}{\sigma}}\right)^{\frac{\rho}{1+\rho}} \\
+(1-\omega)^{\frac{1}{1+\rho}} p_{n}^{\frac{\rho}{1+\rho}}
\end{array}\right] } \\
\frac{P}{\bar{p}_{x}}= & {\left[\begin{array}{c}
\left.\omega^{\frac{1+\rho}{1+\rho}}\left(\left[\begin{array}{c}
\nu^{\frac{1}{1+\sigma}}\left(1+\psi \frac{p_{d}}{\bar{p}_{x}}\right)^{\frac{\sigma}{1+\sigma}} \\
+(1-\nu)^{\frac{1}{1+\sigma}}\left(\frac{\bar{p}_{m}}{\bar{p}_{x}}+\psi \frac{p_{d}}{\bar{p}_{x}}\right)^{\frac{\sigma}{1+\sigma}}
\end{array}\right]^{\frac{1+\sigma}{\sigma}}\right)^{\frac{\rho}{1+\rho}}\right]^{\frac{1+\rho}{\rho}} \\
+(1-\omega)^{\frac{1}{1+\rho}}\left(\frac{p_{n}}{\bar{p}_{x}}\right)^{\frac{\rho}{1+\rho}}
\end{array}\right] }
\end{aligned}
$$

Given these expressions the real exchange rate $\frac{P^{*}}{P}$ can be readily obtained.

In the model calibration, exportable of country 1 is assumed to be the numeraire i.e., $\bar{p}_{x}=1$ for all $t$. The model moments of relative prices as reported in Section 6 are based on the above derivations.

\subsection{Aggregation of sectoral quantities in the model}

As discussed in the data appendix above, GDP, consumption, and investment are obtained at constant (base year) prices. This implies that their relative sectoral prices are also fixed at the base year (i.e., at unity). Accordingly, the sectoral quantities in the model are aggregated at constant relative prices. 
The model parameters are calibrated/scaled by assuming that $p_{n}=\bar{p}_{m}=\bar{p}_{x}=1$; that is, the relative price of nontraded goods and the price of imports at the producer level equal a unit of exportable good (numeraire) in steady state. Since the production of capital goods and distribution services are CRS, their relative prices will also be constant over time. Setting $p_{d}=1$ in the calibration then sets the technology scale parameter $\mu_{d}$ through equation (5) in the paper.

The value function iteration algorithm for computing model results utilizes as natural states the current sectoral shocks and capital stocks for each country. The policy variables for each country are chosen as: investments $s_{x}$ and $s_{n}$; employments, $h_{x}$ and $h_{n}$; allocation of exportables to inputs and exports $x_{x}, x_{n}, x_{d}$, and $e_{x}$; allocation of imports (i.e., $e_{x}^{*}:$ exports of the foreign country) as inputs $m_{x}, m_{n}$, and $m_{d}$.

Employment allocations determine the outputs in the two sectors $y_{x}$ and $y_{n}$. The aggregate output at constant prices is

$$
y=y_{x}+y_{n}
$$

Exportable consumption, $c_{x}$, is determined from (8a). The consumption of importables is given by

$$
c_{m}=e_{x}^{*}-m_{x}-m_{n}-m_{d} .
$$

Knowing $c_{x}$ and $c_{m}$ gets $s_{d}=\psi\left(c_{x}+c_{m}\right)$. Given $s_{x}, x_{x}, m_{x}$, given $s_{n}, x_{n}, m_{n}$, and given $s_{d}, x_{d}, m_{d}$ nontraded inputs $n_{x}, n_{n}$, and $n_{d}$ are obtained from (5). Then $c_{n}$ is obtained from (8b). Then the model's aggregate consumption (at constant prices) is:

$$
c=(1+\psi)\left(c_{x}+c_{m}\right)+c_{n}
$$

The aggregate investment is obtained by summing the input expenditures at constant prices:

$$
i=\sum_{i \equiv x, n} x_{i}+\sum_{i \equiv x, n} m_{i}+\sum_{i \equiv x, n} n_{i}
$$

Aggregate employment is a obtained by simply adding the two sectoral employments, i.e., $h=$ $h_{x}+h_{n}$. 


\section{References}

[1] Ambler, Steve, Emanuela Cardia, and Christian Zimmermann, "International transmission of the business cycle in a multi-sector model," European Economic Review 46 (2002), 273-300

[2] Backus, David, Patrick Kehoe, and Finn Kydland, "International real business cycles". Journal of Political Economy 100 (1992), 745-775

[3] Backus, David, Patrick Kehoe, and Finn Kydland, "Dynamics of the Trade Balance and the Terms of Trade: J-Curve?" American Economic Review, 84 (1994), 84-103

[4] Backus, David and Gregor Smith, "Consumption and real exchange rates in dynamic economies with nontraded goods," Journal of International Economics 35 (1993), 297-316

[5] Baxter, Marianne and Mario Crucini, "Business cycles and the asset structure of foreign trade" International Economic Review 36 (1995), 821-854

[6] Bems, Rudolfs, "Aggregate investment expenditures on tradable and nontradable goods," Review of Economic Dynamics 11 (2008), 852-883

[7] Burstein, Ariel, Joao Neves, Sergio Rebelo, "Distribution costs and real exchange rate dynamics during exchange-rate-based-stablizations" Journal of Monetary Economics 50 (2003), 1189-1214

[8] Jose Manuel Campa and Linda Goldberg, "Distribution margins, imported inputs, and the sensitivity of the CPI to exchange rates," NBER Working Paper 12121 (2006)

[9] Corsetti, Giancarlo and Luca Dedola, "A macroeconomic model of international price discrimination," Journal of International Economics 67 (2005), 129-155

[10] Corsetti, Giancarlo, Luca Dedola, and Sylvain Leduc, "International Risk Sharing and the Transmission of Productivity Shocks," Review of Economic Studies 75 (2008), 443-473 
[11] Heathcote, Jonathan and Fabrizio Perri, "Financial autarky and international business cycles," Journal of Monetary Economics 49 (2002), 601-627

[12] Heathcote, Jonathan and Fabrizio Perri, "Why Has the U.S. Economy Become Less Correlated with the Rest of the World?" AEA Papers and Proceedings 93 (2003), 63-69

[13] Huang, Kevin and Zheng Liu, "Multiple stages of processing and the quantity anomaly," FRB of Kansas City Working Paper 04-05 (2004)

[14] Kehoe, Patrick and Fabrizio Perri, "International business cycles with endogenous incomplete markets," Econometrica 70 (2002), 907-928

[15] Kehoe, Timothy and Kim Ruhl, "Are shocks to the terms of trade shocks to productivity?", Review of Economic Dynamics 11 (2008), 804-819

[16] Kollman, Robert, "Incomplete asset markets and the cross-country consumption correlation puzzle," Journal of Economic Dynamics and Control 20 (1996), 945-961

[17] Kouparitsas, Michael, "North-South Financial Integration and Business Cycles," FRB of Chicago Working Paper 96-10 (1997)

[18] Mendoza, Enrique, "The Terms of Trade, The Real Exchange Rates, and Economic Fluctuations," International Economic Review 36 (1995), 101-137

[19] Oviedo, Marcelo and Rajesh Singh, "International Business Cycles with Multiple-Input Investments," ISU Department of Economics Working Paper \# 11006, April 2011

[20] Pakko, Michael, "International Risk Sharing and Low Cross-Country Consumption Correlations: Are They Really Inconsistent?", Review of International Economics 5 (1997), 386 400

[21] Stockman, Alan and Linda Tesar, "Tastes and technology in a two-country model of the business cycle: Explaining international comovements," American Economic Review 85 (1995), $168-185$ 
[22] Yakhin, Yossi, "Risk sharing and the international consumption correlation puzzle," Mimeo, UCLA (2005) 
Table 1: Cross-country Correlations of Consumption and Output in the Data and in the Present and Previous Studies

\begin{tabular}{lcc}
\hline \hline \multicolumn{1}{c}{ Study / Data } & $\rho\left(c, c^{*}\right)$ & $\rho\left(y, y^{*}\right)$ \\
\hline Data $^{\S}$ : US - EU15 & $0.47(0.32)$ & $0.61(0.40)$ \\
Bakus, Kehoe, and Kyndland (1992) & 0.88 & -0.18 \\
Baxter and Crucini (1995) ${ }^{\dagger}$ & 0.92 & 0.06 \\
Baxter and Crucini (1995) ${ }^{\ddagger}$ & -0.28 & 0.54 \\
Corsetti, Dedola, and Leduc (2008) & 0.30 & 0.38 \\
Heathcote and Perri (2002) & 0.85 & 0.24 \\
Kehoe and Perri (2002) & 0.29 & 0.25 \\
Kollman (1996) & 0.38 & 0.10 \\
Stockman and Tesar (1995) & 0.68 & 0.63 \\
Present Study & 0.27 & 0.45
\end{tabular}

Notes: $\S$ : Annual data for Consumption and GDP at constant prices (1970-2004): OECD National Accounts. The numbers within brackets correspond to the entire available period, 1955-2005. $\rho\left(x, x^{*}\right)$ denotes the cross-country correlation of variable $x$. Figures in the table are the best predictions of the corresponding models. $\dagger$ : incomplete-markets model with trend-stationary shocks; $\ddagger$ : incomplete-markets model with unit-root shocks without cross-country spillovers. 
Figure 1: Crosscountry correlations in two-goods extensions of the BKK model

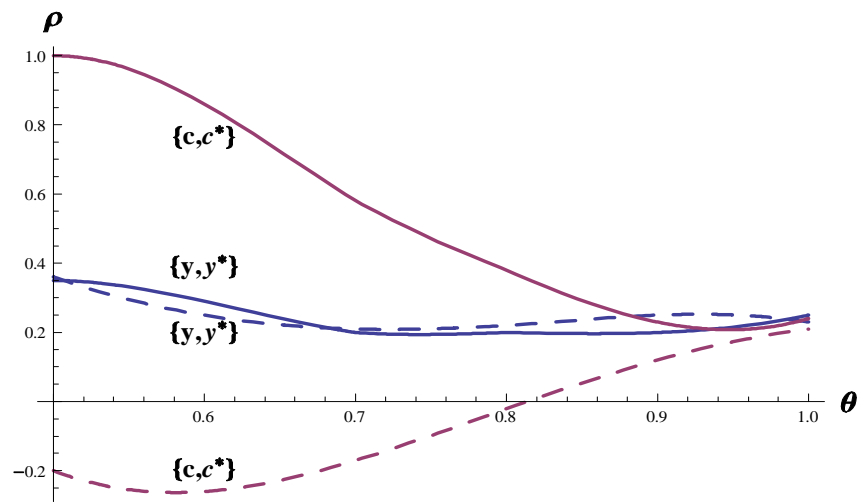

Notes: Solid lines denote crosscountry correlations for the two-goods extension of the BKK model used by Backus, Kehoe, and Kydland (1994) and Heathcote and Perri (2003). Dashed lines denote the same for the variation presented in this paper. 
Table 2: Standard Deviations of Macro Aggregates

\begin{tabular}{|c|c|c|c|c|}
\hline Country & Output & Consumption & Investment & Employment \\
\hline \multicolumn{5}{|l|}{ EU15 } \\
\hline Aggregate & 1.43 & 1.40 & 3.74 & 1.58 \\
\hline Traded & 2.22 & n.a. & n.a. & 1.99 \\
\hline Nontraded & 1.18 & n.a. & n.a. & 1.45 \\
\hline \multicolumn{5}{|l|}{ US } \\
\hline Aggregate & 1.99 & 1.78 & 5.84 & 1.93 \\
\hline Traded & 4.50 & 3.25 & 9.57 & 2.79 \\
\hline Nontraded & 1.87 & 1.25 & 6.35 & 1.83 \\
\hline \multicolumn{5}{|l|}{ UK } \\
\hline Aggregate & 2.17 & 2.26 & 7.67 & 2.75 \\
\hline Traded & 3.12 & 3.03 & 9.49 & 4.23 \\
\hline Nontraded & 3.18 & 1.54 & 8.48 & 2.59 \\
\hline \multicolumn{5}{|l|}{ Japan } \\
\hline Aggregate & 1.97 & 1.64 & 6.1 & 0.83 \\
\hline Traded & 3.22 & 1.19 & n.a. & 1.47 \\
\hline Nontraded & 3.13 & 1.19 & n.a. & 0.77 \\
\hline \multicolumn{5}{|l|}{ Italy } \\
\hline Aggregate & 1.47 & 1.82 & 4.40 & 1.71 \\
\hline Traded & 2.25 & 2.74 & 7.06 & 2.08 \\
\hline Nontraded & 2.23 & 1.32 & 4.52 & 1.67 \\
\hline \multicolumn{5}{|l|}{ Germany } \\
\hline Aggregate & 1.82 & 1.83 & 4.41 & 1.41 \\
\hline Traded & 3.30 & 1.80 & 8.64 & 2.97 \\
\hline Nontraded & 3.21 & 0.99 & 4.86 & 1.16 \\
\hline \multicolumn{5}{|l|}{ France } \\
\hline Aggregate & 1.36 & 1.13 & 4.93 & 1.32 \\
\hline Traded & 2.27 & 1.95 & 8.70 & 1.38 \\
\hline Nontraded & 2.21 & 1.29 & 4.66 & 1.37 \\
\hline \multicolumn{5}{|l|}{ Canada } \\
\hline Aggregate & 2.23 & 2.29 & 6.87 & 2.38 \\
\hline Traded & 4.74 & 3.5 & 10.89 & 3.87 \\
\hline Nontraded & 4.88 & 1.92 & 6.80 & 2.04 \\
\hline
\end{tabular}




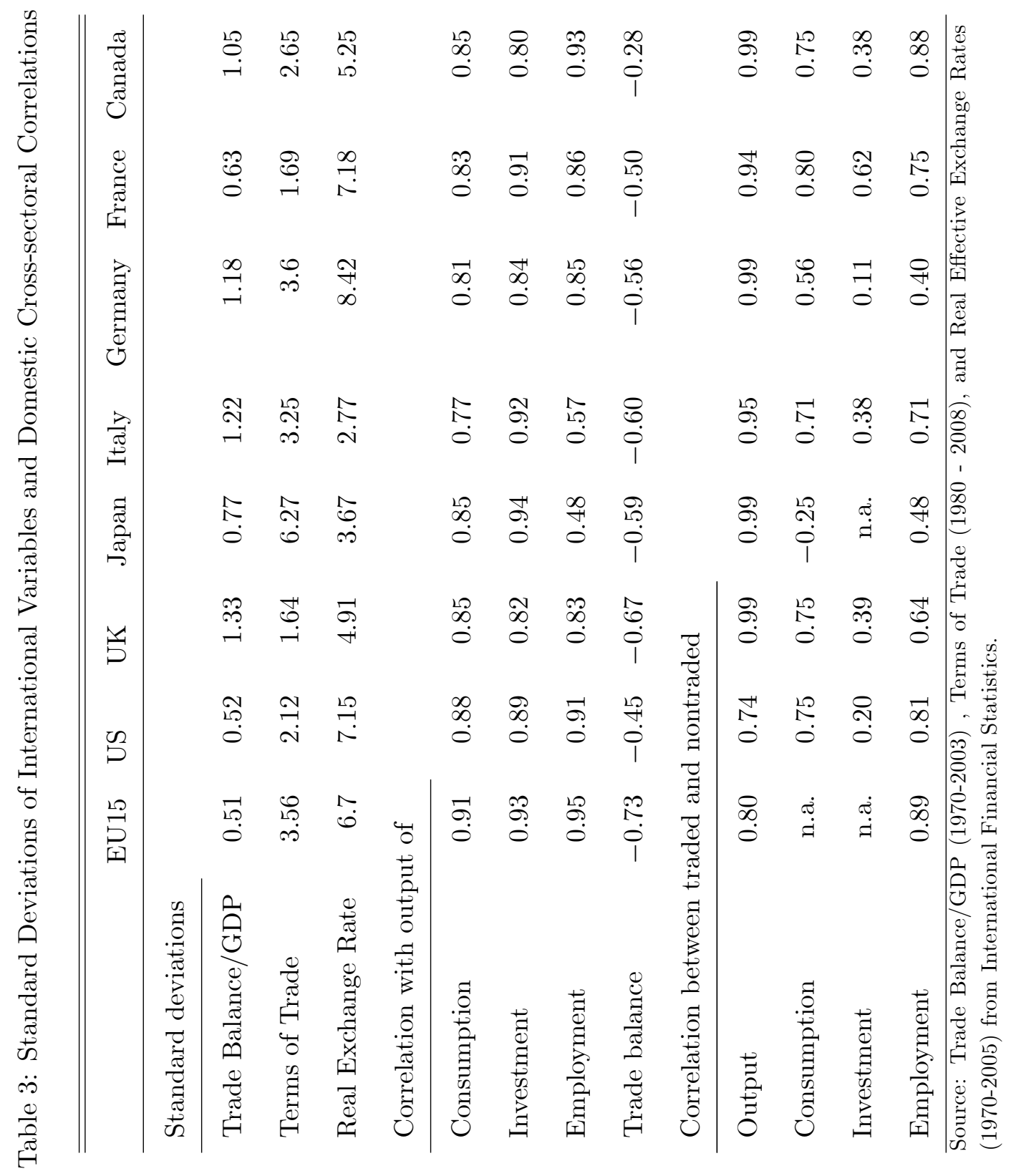




\begin{tabular}{|c|c|c|c|c|c|c|c|}
\hline \multicolumn{2}{|l|}{ D. Employment } & \multirow[b]{2}{*}{ UK } & \multirow[b]{2}{*}{ Japan } & \multirow[b]{2}{*}{ Italy } & \multirow[b]{2}{*}{ Germany } & \multirow[b]{2}{*}{ France } & \multirow[b]{2}{*}{ Canada } \\
\hline Country & US & & & & & & \\
\hline \multicolumn{8}{|l|}{ EU15 } \\
\hline Aggregate & 0.43 & 0.79 & 0.36 & 0.79 & 0.78 & 0.93 & 0.62 \\
\hline Traded & 0.33 & 0.61 & 0.63 & 0.76 & 0.78 & 0.91 & 0.59 \\
\hline Nontraded & 0.39 & 0.81 & 0.01 & 0.68 & 0.51 & 0.92 & 0.63 \\
\hline \multicolumn{8}{|l|}{ US } \\
\hline Aggregate & & 0.77 & 0.31 & -0.07 & 0.05 & 0.37 & 0.79 \\
\hline Traded & & 0.75 & 0.15 & -0.12 & -0.07 & 0.19 & 0.70 \\
\hline Nontraded & & 0.70 & 0.22 & -0.05 & -0.16 & 0.36 & 0.75 \\
\hline \multicolumn{8}{|l|}{ UK } \\
\hline Aggregate & & & 0.49 & 0.42 & 0.33 & 0.65 & 0.84 \\
\hline Traded & & & 0.26 & 0.28 & 0.06 & 0.43 & 0.82 \\
\hline Nontraded & & & 0.21 & 0.48 & 0.04 & 0.65 & 0.83 \\
\hline \multicolumn{8}{|l|}{ Japan } \\
\hline Aggregate & & & & 0.30 & 0.08 & 0.26 & 0.29 \\
\hline Traded & & & & 0.35 & 0.67 & 0.66 & 0.29 \\
\hline Nontraded & & & & -0.02 & -0.28 & -0.06 & -0.07 \\
\hline \multicolumn{8}{|l|}{ Italy } \\
\hline Aggregate & & & & & 0.67 & 0.68 & 0.33 \\
\hline Traded & & & & & 0.66 & 0.77 & 0.17 \\
\hline Nontraded & & & & & 0.13 & 0.46 & 0.37 \\
\hline \multicolumn{8}{|l|}{ Germany } \\
\hline Aggregate & & & & & & 0.82 & 0.20 \\
\hline Traded & & & & & & 0.73 & 0.18 \\
\hline Nontraded & & & & & & 0.67 & -0.06 \\
\hline \multicolumn{8}{|l|}{ France } \\
\hline Aggregate & & & & & & & 0.47 \\
\hline Traded & & & & & & & 0.42 \\
\hline Nontraded & & & & & & & 0.51 \\
\hline
\end{tabular}


Table 4: International correlations: US vis-à-vis EU15 and G7

\begin{tabular}{|c|c|c|c|c|c|c|c|}
\hline & EU15 & UK & Japan & Italy & Germany & France & Canada \\
\hline \multicolumn{8}{|l|}{ Output } \\
\hline Aggregate & 0.61 & 0.79 & 0.32 & 0.47 & 0.31 & 0.41 & 0.79 \\
\hline Traded & 0.37 & 0.74 & 0.22 & -0.49 & 0.09 & 0.30 & 0.88 \\
\hline Nontraded & 0.42 & 0.57 & 0.38 & 0.57 & 0.43 & 0.53 & 0.82 \\
\hline \multicolumn{8}{|l|}{ Consumption } \\
\hline Aggregate & 0.47 & 0.65 & 0.19 & 0.14 & 0.19 & 0.36 & 0.72 \\
\hline Traded & n.a. & 0.53 & -0.62 & -0.01 & 0.35 & 0.16 & 0.67 \\
\hline Nontraded & n.a. & 0.71 & 0.26 & -0.23 & 0.66 & 0.60 & 0.72 \\
\hline \multicolumn{8}{|l|}{ Investment } \\
\hline Aggregate & 0.27 & 0.49 & -0.05 & 0.10 & 0.65 & -0.01 & 0.35 \\
\hline Traded & n.a. & 0.47 & n.a. & -0.37 & 0.08 & -0.18 & 0.66 \\
\hline Nontraded & n.a. & 0.53 & n.a. & -0.08 & 0.71 & 0.16 & 0.26 \\
\hline \multicolumn{8}{|l|}{ Employment } \\
\hline Aggregate & 0.43 & 0.77 & 0.31 & -0.07 & 0.05 & 0.37 & 0.79 \\
\hline Traded & 0.33 & 0.75 & 0.15 & -0.12 & -0.07 & 0.19 & 0.70 \\
\hline Nontraded & 0.39 & 0.70 & 0.22 & -0.05 & -0.16 & 0.36 & 0.75 \\
\hline
\end{tabular}


Table 5: Shares of Inputs in the Total Input Costs of Producing Capital Goods and Distribution Services (in percentages)

\begin{tabular}{|c|c|c|c|}
\hline \multirow[t]{3}{*}{ Sector } & \multicolumn{3}{|c|}{ Input } \\
\hline & \multicolumn{2}{|c|}{ Traded } & \multirow[t]{2}{*}{ Nontraded } \\
\hline & Exportables & Importables & \\
\hline
\end{tabular}

Capital Goods

$\begin{array}{llll}\text { Traded } & 43 & 26 & 31\end{array}$

$\begin{array}{llll}\text { Non-traded } & 25 & 14 & 61\end{array}$

Distribution Services $\quad 15 \quad 2.4 \quad 82.6$

Source: Bureau of Economic Analysis (BEA). Historical-Cost Investment in Private Equipment and Software by Industry (1947-2004); Historical-Cost Investment in Private Structures by Industry (1947-2004); Input-Output Tables 1997 and 2004; Import matrix 1997; Exports and Imports of Goods and Services by Type of Product (1967-2004).

Table 6: Distribution Margins in the Present and Previous (in percentages) Studies

\begin{tabular}{lcccccc}
\hline & Canada & France & Germany & Italy & U.K. & U.S. \\
\cline { 2 - 6 } & 41.2 & 35.0 & 41.5 & 43.3 & 45.4 & 43.4 \\
Burstein, Neves, \& Rebelo (2002) & - & 33.5 & 40.3 & 42.0 & 48.7 & 42.8 \\
Campa \& Goldberg (2005) & 1987 & 1992 & 1997 & 2002 & 2005 & \\
\cline { 2 - 6 } & 39.8 & 42.0 & 45.1 & 46.0 & 46.2 & \\
\hline
\end{tabular}

Source: The BEA's Input-Output Tables for 1987, 1992, 1997, 2002, and 2005 have been utilized for constructing the time series on the U.S. distribution margin. The distribution margin is the value of the wholesale and retail trade component incorporated into the value of the private final consumption of traded goods. 
Table 7: Parameter Values: Benchmark model, the model without multiple input investments (w/o MII), and the model without distribution services (with a unit trade elasticity)

\begin{tabular}{|c|c|c|c|c|}
\hline \multirow[t]{2}{*}{ Notation } & \multirow[t]{2}{*}{ Explanation } & \multicolumn{3}{|c|}{ Parameter Values } \\
\hline & & Benchmark & w/o MII & w/o distribution ${ }^{\S \S}$ \\
\hline
\end{tabular}

Final goods technology
$\left(\theta_{x}, \theta_{n}\right) \quad$ Capital shares in output
$(0.36,0.38)$
$(0.36,0.38)$
$(0.36,0.38)$
$\left(\lambda_{x}, \lambda_{n}\right) \quad$ Productivity shocks
$(3.11,2.78)$
$(3.11,2.78)$

Capital goods technology
$\left(\delta_{x}, \delta_{n}\right) \quad$ Depreciation rates
$(0.085,0.071)$
$(0.085,0.071)$
$(0.085,0.071)$
$\frac{1}{1+\epsilon_{x}}, \frac{1}{1+\epsilon_{m}}$
Elast. of Sub. between $x$ and $m$
$(1,1)$
n.a.
$\left(\alpha_{x}, \alpha_{n}\right) \quad$ Share of expenditure on tradables
$(0.69,0.39)$
$(1,0)$
$(0.68,0.49)$
$\left(\phi_{x}, \phi_{n}\right) \quad$ Share parameter for $x$
$(0.63,0.64)$
(1, n.a.)
$(0.63,0.64)$
$\left(\mu_{x}, \mu_{n}\right) \quad$ Scale parameters
$(2.93,2.52)$
$(1,1)$

Distribution services

\begin{tabular}{|c|c|c|c|c|}
\hline$\left(1+\epsilon_{d}\right)^{-1}$ & Elast. of Sub. between $x$ and $m$ & 1 & 1 & n.a. \\
\hline$\alpha_{d}$ & Share of expenditure on tradables & 0.17 & 0.17 & n.a. \\
\hline$\phi_{d}$ & Share parameter for $x$ & 0.86 & 0.86 & n.a. \\
\hline$\mu_{d}$ & Scale parameter & 1.71 & 1.71 & n.a. \\
\hline$\psi$ & Requirement of distrib. services $^{\dagger}$ & 0.67 & 0.67 & (n.a.,n.a.) \\
\hline
\end{tabular}

\section{Preferences}

\begin{tabular}{|c|c|c|c|c|}
\hline$(1+\sigma)^{-1}$ & Elast. of Sub. between $c_{x}$ and $c_{m}$ & 1 & 1 & 1 \\
\hline$\nu$ & Share of exportables $\ddagger$ & 0.56 & 0.45 & 0.75 \\
\hline$\omega$ & Weight on traded composite & 0.07 & 0.12 & $0.065(0.13)$ \\
\hline$(1+\rho)^{-1}$ & Elasticity of substitution ${ }^{\S}$ & 0.44 & 0.44 & $0.33(0.44)$ \\
\hline$\eta$ & Labor share parameter & -1.92 & -1.92 & -1.93 \\
\hline$\gamma$ & CES utility parameter & -1 & -1 & -1 \\
\hline
\end{tabular}

Notes: $\uparrow$ : Requirements per unit of exportable and importable goods consumed. $\ddagger$ : Share in the consumption of traded goods. $\S$ : Between traded and non-traded goods. $\S \S$ The values within brackets relate to the calibration in which the elasticity of substitution between traded and nontraded consumption is kept unchanged. 
Table 8: VAR Estimate of the Productivity Shocks

$$
\hat{\Lambda}=\left(\begin{array}{rrrr}
0.263 & 0.051 & -0.135 & 0.144 \\
-0.191 & 0.527 & -0.153 & 0.052 \\
-0.135 & 0.144 & 0.263 & 0.051 \\
-0.153 & 0.052 & -0.191 & 0.527
\end{array}\right) \quad \hat{\Sigma}=0.001 \times\left(\begin{array}{llll}
0.502 & 0.088 & 0.16 & 0.036 \\
0.088 & 0.14 & 0.036 & 0.015 \\
0.16 & 0.036 & 0.502 & 0.088 \\
0.036 & 0.015 & 0.088 & 0.14
\end{array}\right)
$$

Source: Output and Employment (1979-2003) - GGDC; Capital stock (1979-2003) for Canada, France, Germany, Italy, and UK - OECD STAN industrial database; For Germany, the capital stock data is available for 1991-2003 only. Capital Stock (1979-2003) for the US is from Bureau of Labor Statistics. 
Table 9: Table of results - Standard deviations and internal correlations

\begin{tabular}{|c|c|c|c|c|c|}
\hline & \multirow{3}{*}{$\begin{array}{c}\operatorname{Data}^{\S} \\
\text { US }[\min -\max ]\end{array}$} & \multirow{3}{*}{$\begin{array}{l}\mathrm{S} \& \mathrm{~T} \\
\text { model }\end{array}$} & \multicolumn{3}{|c|}{ Present Study } \\
\hline & & & Bench- & $\mathrm{w} / \mathrm{o}$ & $\mathrm{w} / \mathrm{o}$ \\
\hline & & & mark & MII & Distrib. ${ }^{\dagger \dagger}$ \\
\hline & (a) & (b) & (c) & (d) & (e) \\
\hline \multicolumn{6}{|c|}{ Standard DeViations $^{\dagger}$} \\
\hline \multicolumn{6}{|l|}{ Output } \\
\hline Aggregate & $1.99[1.36-2.33]$ & 1.87 & 1.63 & 1.66 & $1.74[1.64]$ \\
\hline Traded & $4.50[2.22-4.74]$ & 2.61 & 2.57 & 3.33 & $2.47[2.67]$ \\
\hline Nontraded & $1.87[1.18-4.88]$ & 1.32 & 1.49 & 1.70 & $1.48[1.51]$ \\
\hline \multicolumn{6}{|l|}{ Consumption } \\
\hline Aggregate & $1.78[1.13-2.29]$ & 0.53 & 0.52 & 0.50 & $0.51[0.52]$ \\
\hline Traded & $3.25[1.80-3.50]$ & 0.59 & 0.51 & 0.55 & $0.64[0.67]$ \\
\hline Nontraded & $1.25[0.99-1.92]$ & 0.48 & 0.62 & 0.53 & $0.57[0.63]$ \\
\hline \multicolumn{6}{|l|}{ Investment } \\
\hline Aggregate & $5.84[3.74-7.67]$ & 4.94 & 5.95 & 5.48 & $6.35[5.97]$ \\
\hline Traded & $9.57[7.06-10.89]$ & 7.62 & 9.78 & 12.33 & $8.59[10.38]$ \\
\hline Nontraded & $4.86[4.52-8.48]$ & 3.25 & 6.02 & 5.86 & $5.92[5.99]$ \\
\hline \multicolumn{6}{|l|}{ Hours } \\
\hline Aggregate & $1.93[0.83-2.75]$ & 0.87 & 0.79 & 0.81 & $0.84[0.80]$ \\
\hline Traded & $2.79[1.38-4.23]$ & 1.64 & 1.38 & 2.30 & $1.12[1.39]$ \\
\hline Nontraded & $1.83[0.77-2.59]$ & 0.78 & 0.64 & 0.96 & $0.81[0.62]$ \\
\hline \multicolumn{6}{|c|}{ Trade and Relative PRICES } \\
\hline TB/output & $0.52[0.52-1.33]$ & 0.13 & 0.30 & 0.09 & $0.37[0.32]$ \\
\hline TOT & $2.11[1.64-6.27]$ & 0.75 & 2.37 & 1.34 & $2.22[2.15]$ \\
\hline Price of NT goods & $2.14[1.34-2.14]$ & 0.85 & 2.09 & 1.26 & $2.20[1.99]$ \\
\hline$R E R$ & $7.15[2.77-8.42]$ & 0.81 & 2.46 & 1.38 & $2.06[2.29]$ \\
\hline \multicolumn{6}{|c|}{ Domestic CorRelations } \\
\hline$(T B, y)$ & $-0.45[-0.28-(-0.73)]$ & 0.20 & -0.37 & -0.14 & $-0.23[-0.31]$ \\
\hline$(c, y)$ & $0.88[0.77-0.91]$ & 0.95 & 0.88 & 0.95 & $0.91[0.88]$ \\
\hline$(i, y)$ & $0.88[0.80-0.94]$ & 1.00 & 0.98 & 1.00 & $0.97[0.98]$ \\
\hline$(h, y)$ & $0.91[0.48-0.95]$ & 0.98 & 0.97 & 0.99 & $0.98[0.98$ \\
\hline$\left(y_{x}, y_{n}\right)$ & $0.74[0.74-0.99]$ & 0.27 & 0.60 & 0.13 & $0.69[0.54]$ \\
\hline$\left(c_{T}, c_{n}\right)^{\dagger}$ & $0.75[0.56-0.80]$ & 0.80 & 0.59 & 0.74 & $0.43[0.13]$ \\
\hline$\left(i_{x}, i_{n}\right)$ & $0.35[0.11-0.62]$ & 0.10 & 0.36 & -0.02 & $0.63[0.31]$ \\
\hline$\left(h_{x}, h_{n}\right)$ & $0.64[0.40-0.88]$ & -0.16 & 0.65 & -0.30 & $0.59[0.71]$ \\
\hline
\end{tabular}

Notes: $\S$ : Data moments outside the brackets relate to the US; the numbers inside the brackets indicate the minimum and maximum for G7 and EU15 as presented in Tables 2 and 3 earlier. $\dagger$ : percentage deviations with respect to means. $\dagger \dagger$ : values within square brackets relate to the model without distribution that lets the relative sizes of the two sectors remain as under the benchmark; the values outside relate to the model that matches the sectoral consumption expenditure shares and includes the distribution services within the traded sector output as in ST. The model statistics are computed from 300 simulations of 300 periods each, after disregarding the first 200 periods of each simulation. Column (b) presents results corresponding to Stockman and Tesar (1995) model. Columns (c), (d), and (e) respectively present results from this paper's benchmark model, the model 
Table 10: Table of results - Crosscountry correlations

\begin{tabular}{|c|c|c|c|c|c|}
\hline & \multirow[b]{2}{*}{$\operatorname{Data}^{\S}$} & \multirow[b]{2}{*}{$\mathrm{S} \& \mathrm{~T}$} & \multicolumn{3}{|c|}{ Present Study } \\
\hline & & & Bench- & $\mathrm{w} / \mathrm{o}$ & $\mathrm{w} / \mathrm{o}$ \\
\hline & US-EU15 [min - max] & model & mark & MII & Distrib. $\S \S$ \\
\hline & (a) & (b) & (c) & $(d)$ & (e) \\
\hline \multicolumn{6}{|l|}{ Output } \\
\hline Aggregate & $0.61[0.31-0.79]^{\dagger}$ & 0.44 & 0.45 & 0.41 & $0.46[0.43]$ \\
\hline Traded & $0.37[0.22-0.89]^{\dagger}$ & 0.37 & 0.62 & 0.33 & $0.53[0.56]$ \\
\hline Nontraded & $0.42[0.38-0.82]^{\dagger}$ & 0.27 & 0.21 & 0.26 & $0.20[0.20]$ \\
\hline \multicolumn{6}{|c|}{ Consumption $n^{\ddagger}$} \\
\hline Aggregate & $0.47[0.14-0.72]^{\ddagger}$ & 0.70 & 0.27 & 0.41 & $0.28[0.29]$ \\
\hline Traded & $0.34[-0.01-0.67]^{\ddagger}$ & 0.79 & 0.55 & 0.60 & $0.49[0.81]$ \\
\hline Nontraded & $0.49[-0.23-0.72]^{\ddagger}$ & 0.44 & 0.27 & 0.29 & $0.25[0.29]$ \\
\hline \multicolumn{6}{|l|}{ Investment } \\
\hline Aggregate & $0.27[-0.05-0.65]$ & 0.41 & 0.23 & 0.37 & $0.28[0.22]$ \\
\hline Traded & $0.13[-0.37-0.66]$ & 0.34 & 0.36 & 0.30 & $0.31[0.29]$ \\
\hline Nontraded & $0.32[-0.08-0.53]$ & 0.21 & 0.17 & 0.23 & $0.22[0.16]$ \\
\hline \multicolumn{6}{|l|}{ Hours } \\
\hline Aggregate & $0.43[0.31-0.79]^{\dagger \dagger}$ & 0.54 & 0.63 & 0.50 & $0.67[0.60]$ \\
\hline Traded & $0.33[0.15-0.75]^{\dagger \dagger}$ & 0.36 & 0.93 & 0.32 & $0.91[0.94]$ \\
\hline Nontraded & $0.39[0.22-0.75]^{\dagger \dagger}$ & 0.06 & 0.06 & 0.11 & $0.26[0.01]$ \\
\hline
\end{tabular}

Notes: §: The correlations outside the brackets relate to US vis-à-vis EU15 whenever available; for sectoral consumptions and sectoral investments EU15 series is not available and therefore the numbers indicate averages for US vis-à-vis other countries in G7, as prsented in Table 4. The numbers inside the brackets indicate the minimum and maximum correlations between US and others in G7 and EU15. §§: values within square brackets relate to the model without distribution that lets the relative sizes of the two sectors remain as under the benchmark; the values outside relate to the model that matches the sectoral consumption expenditure shares and includes the distribution services within the traded sector output as in ST.†: After dropping Italy as an outlier. $\ddagger$ : After dropping Japan as an outlier. $\dagger \dagger$ : After drobing Italy and Germany as outliers. 
Table 11: Parameter Values: Benchmark model, the model without multiple input investments (w/o MII), and the model without distribution services (with trade elasticity $=2$ )

\begin{tabular}{|c|c|c|c|c|}
\hline \multirow[t]{2}{*}{ Notation } & \multirow[t]{2}{*}{ Explanation } & \multicolumn{3}{|c|}{ Parameter Values } \\
\hline & & Benchmark & w/o MII & $\mathrm{w} / \mathrm{o}$ distribution ${ }^{\S}$ \\
\hline
\end{tabular}

Final goods technology
$\left(\theta_{x}, \theta_{n}\right) \quad$ Capital shares in output
$(0.36,0.38)$
$(0.36,0.38)$
$(0.36,0.38)$
$\left(\lambda_{x}, \lambda_{n}\right) \quad$ Productivity shocks
$(3.11,2.78)$
$(3.11,2.78)$

Capital goods technology
$\left(\delta_{x}, \delta_{n}\right) \quad$ Depreciation rates
$(0.085,0.071)$
$(0.085,0.071)$
$(0.085,0.071)$
$\frac{1}{1+\epsilon_{x}}, \frac{1}{1+\epsilon_{n}} \quad$ Elast. of Sub. between $x$ and $m$
n.a.
$\left(\alpha_{x}, \alpha_{n}\right) \quad$ Share of expenditure on tradables
$(0.69,0.39)$
$(1,0)$
$(0.68,0.49)$
$\left(\phi_{x}, \phi_{n}\right) \quad$ Share parameter for $x$
$(0.57,0.57)$
(1, n.a.)
$(0.57,0.57)$
$\left(\mu_{x}, \mu_{n}\right) \quad$ Scale parameters
$(2.96,2.53)$
$(1,1)$
$(2.96,2.78)$

Distribution services

$\begin{array}{clccc}\left(1+\epsilon_{d}\right)^{-1} & \text { Elast. of Sub. between } x \text { and } m & 2 & 2 & \text { n.a. } \\ \alpha_{d} & \text { Share of expenditure on tradables } & 0.17 & 0.17 & \text { n.a. } \\ \phi_{d} & \text { Share parameter for } x & 0.72 & 0.72 & \text { n.a. } \\ \mu_{d} & \text { Scale parameter } & 1.75 & 1.71 & \text { n.a. } \\ \left(\psi_{x}, \psi_{m}\right) & \text { Requirement of distrib. services }{ }^{\dagger} & (0.67,0.67) & (0.67,0.67) & \text { (n.a.,n.a.) }\end{array}$

Preferences

\begin{tabular}{|c|c|c|c|c|}
\hline$(1+\sigma)^{-1}$ & Elast. of Sub. between $c_{x}$ and $c_{m}$ & 2 & 2 & 2 \\
\hline$\nu$ & Share of exportables $\ddagger$ & 0.53 & 0.47 & 0.64 \\
\hline$\omega$ & Weight on traded composite & 0.06 & 0.12 & $0.06(0.12)$ \\
\hline$(1+\rho)^{-1}$ & Elasticity of substitution ${ }^{\S}$ & 0.44 & 0.44 & $0.34(0.44)$ \\
\hline$\eta$ & Labor share parameter & -1.92 & -1.92 & -1.93 \\
\hline$\gamma$ & CES utility parameter & -1 & -1 & -1 \\
\hline
\end{tabular}

Notes: $\uparrow$ : Requirements per unit of exportable and importable goods consumed. $\ddagger$ : Share in the consumption of traded goods. $\S$ : Between traded and non-traded goods. $\S$ : The values within brackets relate to the calibration in which the elasticity of substitution between traded and nontraded consumption is kept unchanged. 
Table 12: Hypothetical shocks with (i) no spillovers and (ii) uncorrelated sectoral productivities

$$
\hat{\Lambda}=\left(\begin{array}{cccc}
0.5 & 0.0 & 0.0 & 0.0 \\
0.0 & 0.5 & 0.0 & 0.0 \\
0.0 & 0.0 & 0.5 & 0.0 \\
0.0 & 0.0 & 0.0 & 0.5
\end{array}\right) \quad \hat{\Sigma}=0.001 \times\left(\begin{array}{cccc}
0.5 & 0.0 & 0.1 & 0 . \\
0.0 & 0.5 & 0.0 & 0.1 \\
0.1 & 0.0 & 0.5 & 0.0 \\
0.0 & 0.1 & 0.0 & 0.5
\end{array}\right)
$$


Table 13: Model statistics under (i) a higher trade elasticity; and (ii) simpler productivity shocks

\begin{tabular}{|c|c|c|c|c|c|c|}
\hline & \multicolumn{3}{|c|}{ Import elasticity $=2$} & \multicolumn{3}{|c|}{ Simple Shocks } \\
\hline & Bench- & $\mathrm{w} / \mathrm{o}$ & $\mathrm{w} / \mathrm{o}$ & Bench- & $\mathrm{w} / \mathrm{o}$ & $\mathrm{w} / \mathrm{o}$ \\
\hline & mark & MII & Distrib. $^{\dagger \dagger}$ & mark & MII & Distrib. ${ }^{\dagger \dagger}$ \\
\hline & (a) & (b) & (c) & (d) & (e) & (f) \\
\hline \multicolumn{7}{|c|}{ Standard Deviations ${ }^{\dagger}$} \\
\hline \multicolumn{7}{|l|}{ Output } \\
\hline Aggregate & 1.65 & 1.66 & $1.77[1.66]$ & 2.05 & 2.07 & $1.94[2.07]$ \\
\hline Traded & 2.75 & 3.38 & $2.65[2.88]$ & 2.43 & 3.35 & $2.34[2.55]$ \\
\hline Nontraded & 1.50 & 1.70 & $1.49[1.51]$ & 2.43 & 3.03 & $2.26[2.49]$ \\
\hline \multicolumn{7}{|l|}{ Consumption } \\
\hline Aggregate & 0.52 & 0.47 & $0.50[0.52]$ & 0.91 & 0.74 & $0.80[0.89]$ \\
\hline Traded & 0.52 & 0.44 & $0.64[0.67]$ & 0.65 & 0.68 & $0.70[0.75]$ \\
\hline Nontraded & 0.62 & 0.55 & $0.57[0.63]$ & 1.15 & 0.87 & $1.06[1.17]$ \\
\hline \multicolumn{7}{|l|}{ Investment } \\
\hline Aggregate & 6.04 & 5.65 & $6.46[6.11]$ & 7.25 & 7.00 & $7.24[7.39]$ \\
\hline Traded & 11.22 & 13.55 & $10.02[12.29]$ & 11.56 & 12.70 & 9.39 [12.39] \\
\hline Nontraded & 6.03 & 5.90 & $6.05[6.10]$ & 10.40 & 10.85 & $9.48[10.62]$ \\
\hline \multicolumn{7}{|l|}{ Hours } \\
\hline Aggregate & 0.81 & 0.83 & $0.87[0.82]$ & 0.92 & 0.96 & $0.87[0.93]$ \\
\hline Traded & 1.44 & 2.38 & $1.22[1.54]$ & 1.55 & 2.49 & $1.37[1.45]$ \\
\hline Nontraded & 0.63 & 0.97 & $0.77[0.63]$ & 0.85 & 1.82 & $0.86[0.90]$ \\
\hline \multicolumn{7}{|c|}{ Trade and Relative PRICES } \\
\hline TB/output & 0.40 & 0.13 & $0.54[0.46]$ & 0.49 & 0.14 & $0.65[0.54]$ \\
\hline TOT & 1.79 & 1.19 & $1.62[1.57]$ & 2.89 & 1.63 & $2.71[2.65]$ \\
\hline Price of NT goods & 1.96 & 1.25 & $2.07[1.85]$ & 3.17 & 1.89 & $3.32[3.02]$ \\
\hline$R E R$ & 2.46 & 1.57 & $1.72[1.85]$ & 3.34 & 1.92 & $2.85[3.16]$ \\
\hline \multicolumn{7}{|c|}{ Domestic Correlations } \\
\hline$(T B, y)$ & -0.23 & -0.02 & $-0.06[-0.19]$ & -0.50 & -0.32 & $-0.37[-0.45]$ \\
\hline$(c, y)$ & 0.88 & 0.94 & $0.91[0.89]$ & 0.92 & 0.94 & $0.92[0.92]$ \\
\hline$(i, y)$ & 0.97 & 0.99 & $0.95[0.96]$ & 0.96 & 0.99 & $0.94[0.96]$ \\
\hline$(h, y)$ & 0.99 & 0.99 & $0.99[0.99]$ & 0.97 & 0.98 & $0.97[0.97]$ \\
\hline$\left(y_{x}, y_{n}\right)$ & 0.54 & 0.12 & $0.61[0.47]$ & 0.33 & -0.26 & $0.42[0.25]$ \\
\hline$\left(c_{T}, c_{n}\right)$ & 0.58 & 0.74 & $0.41[0.13]$ & 0.70 & 0.74 & $0.40[0.01]$ \\
\hline$\left(i_{x}, i_{n}\right)$ & 0.26 & -0.02 & $0.40[0.18]$ & -0.21 & -0.41 & $0.17[-0.22]$ \\
\hline$\left(h_{x}, h_{n}\right)$ & 0.68 & -0.32 & $0.64[0.60]$ & 0.48 & -0.64 & $0.28[0.51]$ \\
\hline
\end{tabular}

Notes: $\uparrow \dagger$ : values within square brackets relate to the model without distribution that lets the relative sizes of the two sectors remain as unde 6 the benchmark; the values outside relate to the model that matches the sectoral consumption expenditure shares and includes the distribution services within the traded sector output as in ST. 
Table 14: Model statistics under (i) a higher trade elasticity; and (ii) simpler productivity shocks

\begin{tabular}{|c|c|c|c|c|c|c|}
\hline & \multicolumn{3}{|c|}{ Import elasticity $=2$} & \multicolumn{3}{|c|}{ Simple Shocks } \\
\hline & Bench- & $\mathrm{w} / \mathrm{o}$ & $\mathrm{w} / \mathrm{o}$ & Bench- & $\mathrm{w} / \mathrm{o}$ & $\mathrm{w} / \mathrm{o}$ \\
\hline & mark & MII & Distrib. $\S \S$ & mark & MII & Distrib. ${ }^{\dagger \dagger}$ \\
\hline & (a) & (b) & (c) & (d) & (e) & (f) \\
\hline \multicolumn{7}{|l|}{ Output } \\
\hline Aggregate & 0.41 & 0.39 & $0.41[0.39]$ & 0.24 & 0.23 & $0.24[0.22]$ \\
\hline Traded & 0.40 & 0.27 & $0.34[0.34]$ & 0.50 & 0.17 & $0.38[0.42]$ \\
\hline Nontraded & 0.20 & 0.25 & $0.19[0.19]$ & 0.09 & 0.18 & $0.02[0.09]$ \\
\hline \multicolumn{7}{|c|}{ Consumption $n^{\ddagger}$} \\
\hline Aggregate & 0.28 & 0.38 & $0.30[0.29]$ & 0.19 & 0.24 & $0.21[0.20]$ \\
\hline Traded & 0.53 & 0.53 & $0.54[0.79]$ & 0.26 & 0.43 & $0.39[0.77]$ \\
\hline Nontraded & 0.29 & 0.33 & $0.28[0.31]$ & 0.26 & 0.19 & $0.27[0.28]$ \\
\hline \multicolumn{7}{|l|}{ Investment } \\
\hline Aggregate & 0.20 & 0.37 & $0.24[0.17]$ & -0.12 & 0.15 & $-0.16[-0.14]$ \\
\hline Traded & 0.04 & 0.28 & $-0.02[-0.07]$ & 0.60 & 0.18 & $0.38[0.50]$ \\
\hline Nontraded & 0.17 & 0.23 & $0.17[0.13]$ & 0.09 & 0.18 & $0.02[0.10]$ \\
\hline \multicolumn{7}{|l|}{ Hours } \\
\hline Aggregate & 0.56 & 0.46 & $0.55[0.52]$ & 0.28 & 0.27 & $0.34[0.25]$ \\
\hline Traded & 0.75 & 0.22 & $0.60[0.56]$ & 0.83 & 0.13 & $0.78[0.86]$ \\
\hline Nontraded & 0.10 & 0.09 & $0.38[0.00]$ & -0.25 & 0.14 & $-0.08[-0.25]$ \\
\hline
\end{tabular}

Notes: $\S \S$ : values within square brackets relate to the model without distribution that lets the relative sizes of the two sectors remain as under the benchmark; the values outside relate to the model that matches the sectoral consumption expenditure shares and includes the distribution services within the traded sector output as in ST. 
Figure 2: A shock to the traded sector - Impulse response functions from the benchmark model and the model in which sectoral goods serve as their own capital
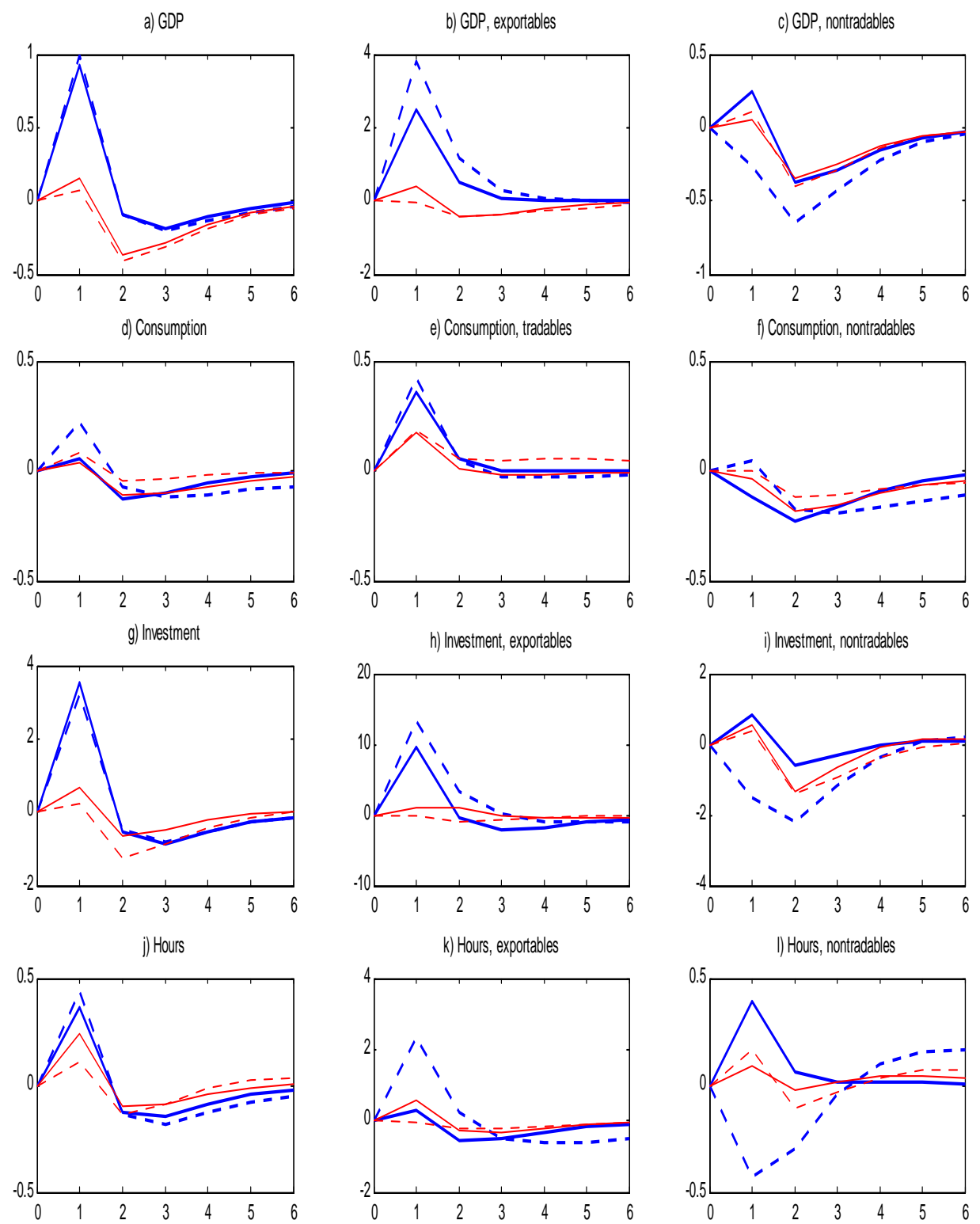

Notes: Darker (blue when colors are available) lines are used for country 1 and lighter (red) lines are used for country 2. For each country, solid (dashed) lines are used for impulse response functions of the model that includes (excludes) the multiple-input technologies in the production of capital goods. 
Figure 3: A shock to the nontraded sector - Impulse response functions from the benchmark model and the model in which sectoral goods serve as their own capital
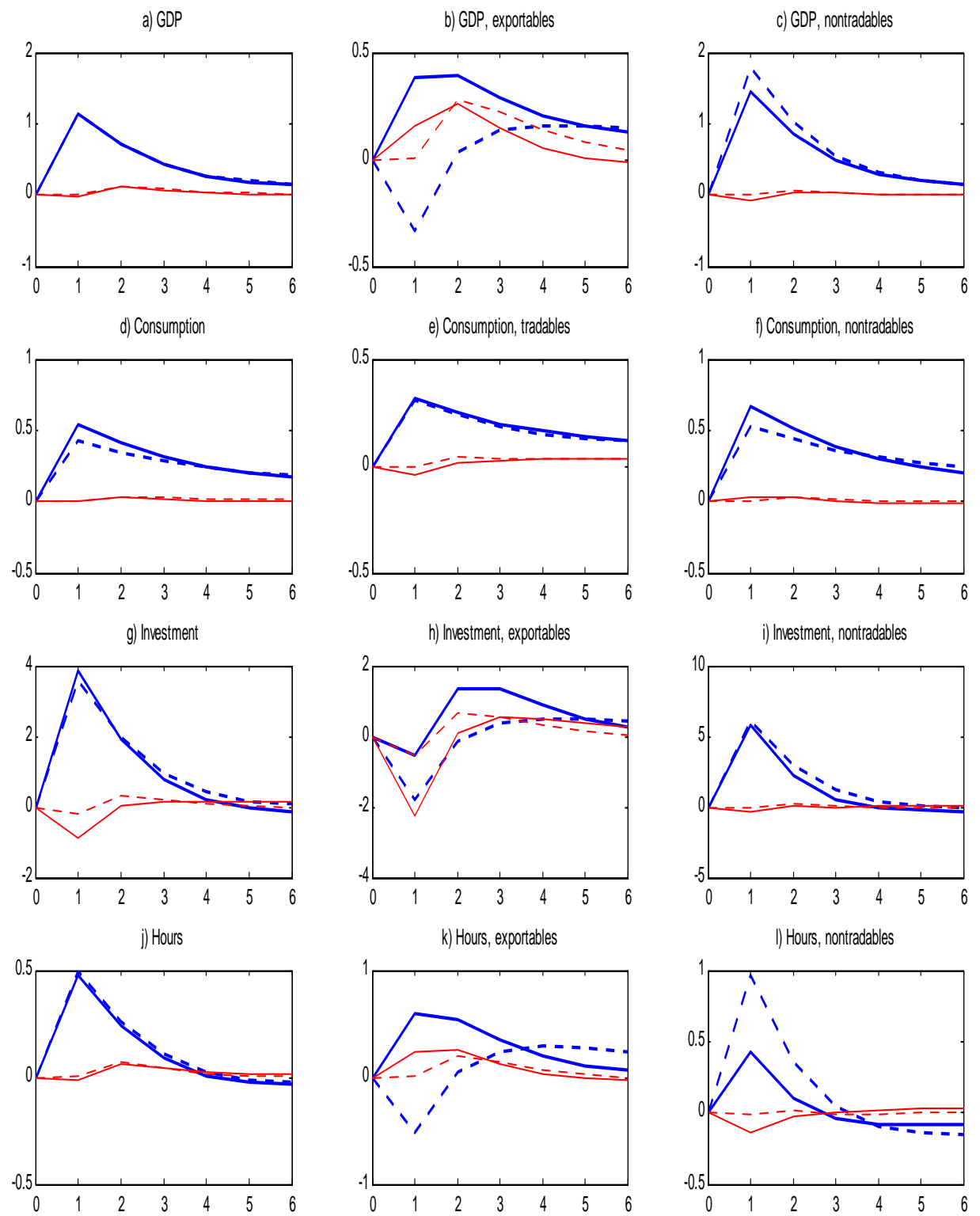

Notes: Darker (blue when colors are available) lines are used for country 1 and lighter (red) lines are used for country 2. For each country, solid (dashed) lines are used for impulse response functions of the model that includes (excludes) the multiple-input technologies in the production of capital goods. 
Figure 4: A shock to the traded sector - Impulse response functions with and without distribution services
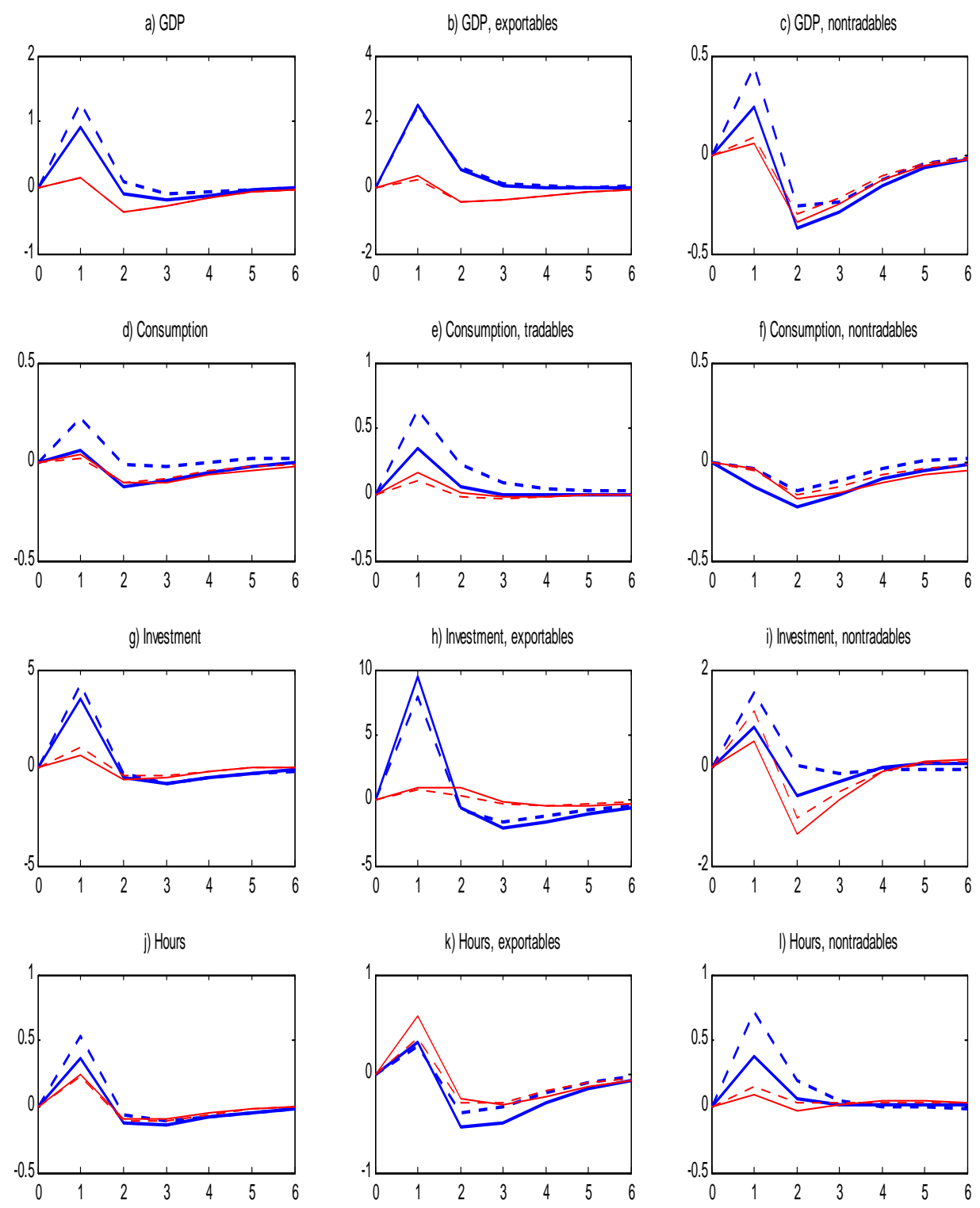

Notes: Darker (blue when colors are available) lines are used for country 1 and lighter (red) lines are used for country 2. For each country, solid (dashed) lines are used for impulse response functions of the model that includes (excludes) distribution services. 
Figure 5: A shock to the nontraded sector - Impulse response functions with and without distribution services
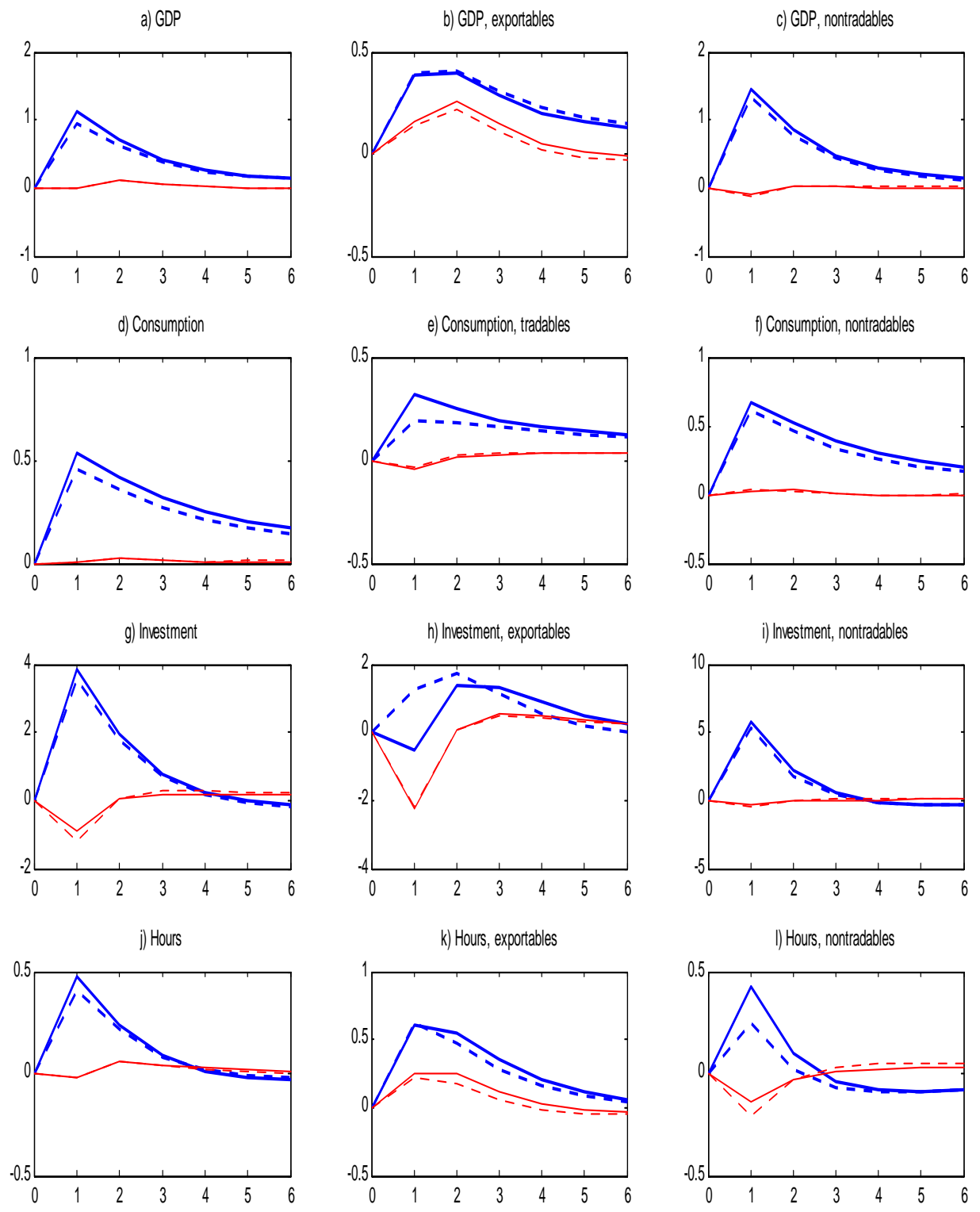

Notes: Darker (blue when colors are available) lines are used for country 1 and lighter (red) lines are used for country 2. For each country, solid (dashed) lines are used for impulse response functions of the model that includes (excludes) distribution services. 
Table 15: Pairwise Cross-country Correlations for G7 and EU15

\begin{tabular}{|c|c|c|c|c|c|c|c|}
\hline A. Output & & & & & & & \\
\hline Country & US & UK & Japan & Italy & Germany & France & Canada \\
\hline \multicolumn{8}{|l|}{ EU15 } \\
\hline Aggregate & 0.61 & 0.68 & 0.69 & 0.85 & 0.74 & 0.90 & 0.66 \\
\hline Traded & 0.37 & 0.60 & 0.66 & 0.79 & 0.79 & 0.70 & 0.50 \\
\hline Nontraded & 0.42 & 0.35 & 0.57 & 0.60 & 0.87 & 0.51 & 0.21 \\
\hline \multicolumn{8}{|l|}{ US } \\
\hline Aggregate & & 0.79 & 0.32 & 0.47 & 0.31 & 0.41 & 0.79 \\
\hline Traded & & 0.74 & 0.22 & -0.49 & 0.09 & 0.30 & 0.88 \\
\hline Nontraded & & 0.57 & 0.38 & 0.57 & 0.43 & 0.53 & 0.82 \\
\hline \multicolumn{8}{|l|}{ UK } \\
\hline Aggregate & & & 0.38 & 0.51 & 0.16 & 0.50 & 0.81 \\
\hline Traded & & & 0.25 & 0.71 & 0.15 & 0.34 & 0.76 \\
\hline Nontraded & & & 0.13 & 0.62 & 0.19 & 0.20 & 0.68 \\
\hline \multicolumn{8}{|l|}{ Japan } \\
\hline Aggregate & & & & 0.51 & 0.71 & 0.57 & 0.19 \\
\hline Traded & & & & 0.44 & 0.72 & 0.51 & 0.24 \\
\hline Nontraded & & & & 0.47 & 0.73 & 0.63 & 0.18 \\
\hline \multicolumn{8}{|l|}{ Italy } \\
\hline Aggregate & & & & & 0.60 & 0.72 & 0.60 \\
\hline Traded & & & & & 0.45 & 0.57 & 0.56 \\
\hline Nontraded & & & & & 0.51 & 0.59 & 0.55 \\
\hline \multicolumn{8}{|l|}{ Germany } \\
\hline Aggregate & & & & & & 0.64 & 0.15 \\
\hline Traded & & & & & & 0.47 & 0.13 \\
\hline Nontraded & & & & & & 0.60 & 0.22 \\
\hline \multicolumn{8}{|l|}{ France } \\
\hline Aggregate & & & & & & & 0.51 \\
\hline Traded & & & & & & & 0.19 \\
\hline Nontraded & & & & & & & 0.18 \\
\hline $\begin{array}{l}\text { Source: Ou } \\
\text { database; } \\
\text { Investment } \\
\text { for German }\end{array}$ & it an & $\begin{array}{l}\text { Emp } \\
\text { ion } \\
\text { 03) f } \\
\text { able }\end{array}$ & $\begin{array}{l}\text { oyment } \\
1970-20 \\
\text { om OE } \\
\text { or } 1991\end{array}$ & $\begin{array}{l}1979-20 \\
3 \text { ) from } \\
\text { D STAI } \\
2003 \text { onl }\end{array}$ & $\begin{array}{l}\text { 3) from G( } \\
\text { OECD Na } \\
\text { database; }\end{array}$ & $\begin{array}{l}\text { DC 60-1 } \\
\text { ional A } \\
\text { Investm }\end{array}$ & $\begin{array}{l}\text { dustry } \\
\text { counts; } \\
\text { at data }\end{array}$ \\
\hline
\end{tabular}




\begin{tabular}{|c|c|c|c|c|c|c|c|}
\hline \multicolumn{2}{|c|}{ B. Consumption } & \multirow[b]{2}{*}{ UK } & \multirow[b]{2}{*}{ Japan } & \multirow[b]{2}{*}{ Italy } & \multirow[b]{2}{*}{ Germany } & \multirow[b]{2}{*}{ France } & \multirow[b]{2}{*}{ Canada } \\
\hline Country & US & & & & & & \\
\hline \multicolumn{8}{|l|}{ EU15 } \\
\hline Aggregate & 0.47 & 0.69 & 0.59 & 0.72 & 0.69 & 0.82 & 0.71 \\
\hline Traded & n.a. & n.a. & n.a. & n.a. & n.a. & n.a. & n.a. \\
\hline Nontraded & n.a. & n.a. & n.a. & n.a. & n.a. & n.a. & n.a. \\
\hline \multicolumn{8}{|l|}{ US } \\
\hline Aggregate & & 0.65 & 0.19 & 0.14 & 0.19 & 0.36 & 0.72 \\
\hline Traded & & 0.53 & -0.62 & -0.01 & 0.35 & 0.16 & 0.67 \\
\hline Nontraded & & 0.71 & 0.26 & -0.23 & 0.66 & 0.60 & 0.72 \\
\hline \multicolumn{8}{|l|}{ UK } \\
\hline Aggregate & & & 0.47 & 0.48 & 0.12 & 0.57 & 0.76 \\
\hline Traded & & & -0.40 & 0.44 & 0.33 & 0.48 & 0.60 \\
\hline Nontraded & & & 0.45 & 0.23 & 0.07 & 0.48 & 0.69 \\
\hline \multicolumn{8}{|l|}{ Japan } \\
\hline Aggregate & & & & 0.21 & 0.55 & 0.48 & 0.32 \\
\hline Traded & & & & -0.52 & 0.49 & -0.58 & -0.58 \\
\hline Nontraded & & & & 0.20 & 0.10 & 0.51 & 0.69 \\
\hline \multicolumn{8}{|l|}{ Italy } \\
\hline Aggregate & & & & & 0.29 & 0.63 & 0.33 \\
\hline Traded & & & & & 0.79 & 0.56 & 0.19 \\
\hline Nontraded & & & & & 0.51 & 0.24 & -0.01 \\
\hline \multicolumn{8}{|l|}{ Germany } \\
\hline Aggregate & & & & & & 0.40 & 0.34 \\
\hline Traded & & & & & & 0.77 & 0.28 \\
\hline Nontraded & & & & & & 0.32 & 0.31 \\
\hline \multicolumn{8}{|l|}{ France } \\
\hline Aggregate & & & & & & & 0.48 \\
\hline Traded & & & & & & & 0.22 \\
\hline Nontraded & & & & & & & 0.50 \\
\hline
\end{tabular}




\begin{tabular}{|c|c|c|c|c|c|}
\hline C. Investment & & & & & \\
\hline Country & UK & Italy & Germany & France & Canada \\
\hline \multicolumn{6}{|l|}{ US } \\
\hline Aggregate & 0.17 & 0.18 & 0.63 & -0.19 & 0.39 \\
\hline Traded & 0.44 & -0.13 & 0.14 & -0.16 & 0.67 \\
\hline Nontraded & 0.20 & -0.14 & 0.54 & -0.25 & -0.28 \\
\hline \multicolumn{6}{|l|}{ UK } \\
\hline Aggregate & & -0.33 & 0.34 & 0.57 & 0.46 \\
\hline Traded & & 0.48 & 0.29 & 0.17 & 0.40 \\
\hline Nontraded & & -0.15 & 0.45 & 0.55 & 0.54 \\
\hline \multicolumn{6}{|l|}{ Italy } \\
\hline Aggregate & & & 0.68 & 0.53 & 0.56 \\
\hline Traded & & & 0.54 & 0.57 & 0.45 \\
\hline Nontraded & & & 0.75 & 0.42 & 0.57 \\
\hline \multicolumn{6}{|l|}{ Germany } \\
\hline Aggregate & & & & -0.58 & -0.53 \\
\hline Traded & & & & 0.30 & -0.31 \\
\hline Nontraded & & & & -0.41 & -0.73 \\
\hline \multicolumn{6}{|l|}{ France } \\
\hline Aggregate & & & & & 0.51 \\
\hline Traded & & & & & 0.06 \\
\hline Nontraded & & & & & 0.63 \\
\hline
\end{tabular}

